Research Article

\title{
Return Mode Selection and Pricing Strategy for a Dual-Channel Retailer
}

\author{
Xiaojian Hu, ${ }^{1,2}$ Shuai Feng $\mathbb{D}^{1,3}$ Jiqiong Liu $\mathbb{D}^{1,4}$ Aifeng Yang, ${ }^{1,2}$ Guanxiong Wang $\mathbb{D}{ }^{1}$ \\ and Hui $\mathrm{Xu}^{5}$ \\ ${ }^{1}$ School of Management, Hefei University of Technology, Hefei 230009, China \\ ${ }^{2}$ Key Laboratory of Process Optimization and Intelligent Decision-Making, Ministry of Education, Hefei 23009, China \\ ${ }^{3}$ School of Business, Fuyang Normal University, Fuyang 236037, China \\ ${ }^{4}$ Anhui Provincial Key Laboratory of Regional Logistics Planning and Modern Logistics Engineering, Fuyang 236037, China \\ ${ }^{5}$ Institute of Logistics, Beijing Wuzi University, Beijing 101149, China
}

Correspondence should be addressed to Shuai Feng; fengshuai@mail.hfut.edu.cn

Received 8 March 2020; Revised 2 June 2020; Accepted 1 July 2020; Published 1 August 2020

Academic Editor: Xiaohua Ding

Copyright ( $\odot 2020$ Xiaojian Hu et al. This is an open access article distributed under the Creative Commons Attribution License, which permits unrestricted use, distribution, and reproduction in any medium, provided the original work is properly cited.

\begin{abstract}
With the rapid development of e-commerce and the economy, an increasing number of retailers are adopting a dual-channel retail strategy (DCRS), which allows customers to return unsatisfactory products, provided that their complaints are reasonable, and receive a full refund. This paper studies the pricing strategies of an integrated dual-channel retailer (DCR) when it provides return policies to customers, including original channel return, fixed cross-channel return, and relaxed cross-channel return. The relationship between the DCR's system performance and channel pricing is impacted by customer channel preferences, and the return rates of different channels are discussed. The results show that the greater the difference in customer preferences between channels is, the greater the profitability of the DCR will be. A fixed cross-channel return model should be selected when the return rate in the online channel is higher or the cross-channel return rate is lower; otherwise, the original channel return model should be selected. When the return rate of a certain channel is high, the retailer should increase the price in that channel and reduce the pricing of its competing channel to compensate for the loss caused by the returns and transfer sales between channels. A selective return policy can not only improve the flexibility of business operations and enhance competitive advantage but also provide convenient customer returns and enhance consumers' sense of security.
\end{abstract}

\section{Introduction}

With the rapid development of the Internet and third-party logistics providers, online sales channels have experienced growth in their customer bases. Many retailers have established online sales channels (online stores) based on existing offline sales channels (physical stores) and adopted a dual-channel retail strategy (DCRS) to obtain greater market share and economic profits. Such a strategy provides several advantages for retail enterprises. For example, it allows retailers to reach a wider customer base and increase revenue [1]. In addition, it enables retailers to meet the growing consumer demand for multichannel shopping. Therefore, using a DCRS can increase customer loyalty and satisfaction and increase the flexibility of the retailer's supply chain. On the other hand, because customers do not experience a product before they purchase it online, the transfer from the traditional offline retail system to a DCRS may significantly increase in the number of customer returns. In the United States and Canada, the total value of returns to merchants is approximately $\$ 100$ and $\$ 10$ billion dollars each year, respectively $[2,3]$. An Invesp infographic of online return rates shows that online shoppers return at least $30 \%$ of their purchases, while in physical stores, fewer than $9 \%$ of customers return their purchases. (The top attributes that customers look for in product returns and how e-tailers 
deliver, http://landmarkglobal.com/trends-insights/topattributes-customers-look-product-returns-e-tailers-deliver/ .) Akçay et al. [2] and Mostard and Teunter [4] also confirmed this, pointing out that the return rate of fashion products in offline physical stores is approximately 35\%; as a comparison, the return rate of online channels is as high as $75 \%$. Thus, product returns are no longer a small part of the business process. The phenomenon of customer return is not unique in the retail field but also exists in other contexts, which have been a focus of research. For example, Krishnamoorthy et al. [5] introduced the concept of cancellation of flight/train/bus tickets for a journey at a future date, and the inventory problem of queuing systems was studied under the condition that customers are allowed to cancel (return) the sold goods before their expiration. Later, these researchers also conducted indepth research on this issue and achieved convincing results $[6,7]$. To increase customer loyalty, promote sales, or comply with legal requirements, many retailers choose to provide customers with loose return policies, such as full money-back guarantees (MBGs). McWilliams [8] found that in a dual-channel environment, both traditional physical retail channels and online channels generally provide return services. Return policies are very popular with customers because they can return undamaged products for any reason and obtain a full refund $[2,9]$. In addition, a return policy can reduce perceived risk and encourage purchases, thereby increasing the customer's willingness to buy and ultimately pay [10]. From the perspective of the retailer (or other merchants engaged in sales activities), although a return policy improves customer satisfaction and stimulates sales, it is also accompanied by a large number of product returns and the high associated processing costs, which in turn affect merchants' profitability $[11,12]$. US sellers spend approximately $\$ 100$ billion annually on processing returns and related logistics [13], and each seller loses an average of $3.8 \%$ of its revenue [14].

Thus, the return policies that retailers offer customers offer both advantages and disadvantages, which require a retailer to consider the following issues when formulating return policy: is it necessary to offer a return policy to customers? When and how should retailers adopt a return policy? What kind of return policy should be adopted? Prior studies have examined the above issues from different perspectives and pointed out that some retailers will choose to adopt tight return policies, such as a partial refund policy, to reduce and limit the costs of handling returns and related reverse logistics [15-17] or even not to offer any return policy [18]. However, in some cases, retailers may adopt a more relaxed return policy, such as an MBG [19-21]. Other studies have compared the retail system's performance in the absence of refund policy to that under a full refund policy [22-24]. However, most studies have focused on the traditional supply chain environment [25-28] and a singleretailer system $[2,17]$ or two-retailer system $[22,29,30]$ and less on issues related to customer returns when dual-channel retailers implement a DCRS.
Retailers adopting a DCRS can simultaneously exploit the advantages of both channels. On the one hand, as mentioned above, retailers can reach a wider customer base through online sales channels to gain greater market share; on the other hand, retailers can use the desirable characteristics of traditional offline sales channels such as display and experience to reduce customers' uncertainty about products and thereby promote a greater variety of product types to consumers in online sales channels, in turn reducing the return rates of products. In addition, compared with single-channel retailers (online or offline), retailers adopting a DCRS can have more options when processing customer returns. Many DCRs (for example, Wal-Mart or Toys "R" Us) only offer same-channel returns, in which items purchased from their physical stores (online stores) must be returned to physical stores (online stores). Many other companies, such as Macy's, Sears, and Best Buy, allow cross-channel returns, and all of them have added return windows to physical stores to facilitate customer returns. Customers returning through physical stores can simplify the return procedure, shorten the return time, and save shipping costs for returns. A survey by Hybris shows that more than $80 \%$ of customers would be loyal to retailers that provide multichannel integration services, and $28 \%$ of customers believe that having a cross-channel return service that allows online purchases and offline returns is the most important part of the integrated channel marketing experience. Cross-channel return services can increase sales and customer satisfaction for online stores; in addition, they attract customers to physical stores, create more cross-selling opportunities for physical stores, and generate additional revenue $[1,31]$.

However, DCRS also has inevitable drawbacks; for example, it may generate internal competition due to incompatible goals between channels and then cause channel conflicts. Many studies have revealed considered conflicts and possible coordination strategies between two channels owned by a single retailer or different firms [32-35]. Customer return issues in single- or two-retailer systems have also been studied in depth [17, 36-38]. However, few studies have examined the issue of customer returns under a DCRS adopted by a single retailer. Radhi and Zhang [39] studied the optimal pricing problem of a dual-channel retailer using a DCRS under integrated and nonintegrated decisionmaking, but they did not include all possible return modes or study the choice among these different modes. In addition, other studies [40,41] have found that the use of a single decision maker allows a fully coordinated or centralized monopoly system to maximize the total profit of the system. Thus, this paper studies the problems of optimal pricing strategies under different return modes and the choice of return mode when an integrated dual-channel retailer using a DCRS is the sole decision maker. Specifically, we study the following problems when an integrated DCR, which acts as the sole decision maker in the system and adopts a DCRS, provides return services to customers:

(1) What are the possible return modes for a dualchannel retailer using a DCRS? How can the optimal 
channel pricing decisions of products under different return modes be determined?

(2) What is the system performance of the DCR under different return modes?

(3) What is the effect of customer channel preferences and return rates on the system performance and optimal channel prices of the DCR?

(4) How does a DCR choose the appropriate return mode for different customer channel preferences and return rate environments?

To answer the above questions, we propose and investigate three return modes according to the different return channels available to customers: the original channel return mode, the fixed cross-channel return mode, and the random cross-channel return mode. When comparing these different return modes, the system performance of the DCR is proxied by the total profit of the system, and the optimal channel prices of products are determined by the objective of an integration problem to maximize the total profit. Furthermore, we analyse the changing relationship between the total profits under different return modes and the customer channel preference as well as the return rate of each channel, with the aim of helping DCR make appropriate return mode choices when facing different customer channel preferences and return rate environments. The analysis reveals that both the customer channel preferences and the return rate of each channel are important factors affecting the optimal pricing decisions and total profit under different return modes, which also means that the choice of the optimal return mode for DCR depends on the value of each parameter. Based on the decision results for the optimal pricing and total profit under each return mode, we identify the rules that govern the change in the total profit and optimal pricing of DCR system while considering customer channel preferences and return rate through numerical analysis. We then experimentally determine the corresponding relationship between the values of return rate parameters and the optimal return mode.

The remainder of this paper is organized as follows. Section 2 reviews the relevant literature. The discussion of the original channel return model and the optimal pricing strategy is provided in Section 3. The models and optimal pricing strategies of the fixed cross-channel return mode and relaxed cross-channel return mode are discussed in Sections 4 and 5, respectively. Section 6 presents the numerical analysis of customer channel preferences and the return rate parameters for the three return modes and offers managerial insights. Finally, conclusions and suggestions for future research are presented in Section 7.

\section{Literature Review}

Multiple problems have arisen from the development of online direct sales channels on the basis of traditional sales channels, such as channel competition and coordination, dual-channel pricing, and customer return policy, and these have gradually given rise to a heated debate among scholars.
Two streams of literature are related to our research: the first examines dual-channel systems, and the second discusses return policies. Many studies have analysed dual-channel systems, but most of these studies have considered dualchannel systems under two settings: the manufacturer-retailer setting and DCR setting. The dual-channel system in the manufacturer-retailer setting consists of a manufacturer that sells a single product to customers through the manufacturer-owned online store and an independent retailer. In this setting, the online direct sales channel and offline sales channel are operated by different stakeholders (the manufacturer and retailer), and different types of competition may arise between the two channels due to the inconsistency of their objectives: price competition [30, 42-45], service competition [46-48], competition in product availability [49-51], etc. According to Kevin Chiang et al. [42], the introduction of a manufacturer's online direct sales channel will damage the interests of the retailer, which means that the retailer has to reduce the sale price to stimulate demand in the offline channel. Park and Keh [52] studied the dualchannel pricing equilibrium when a manufacturer with an online direct sales channel acts as the leader or an offline channel retailer as the leader. They further compared the profitability of the supply chain of a single traditional channel with a dual-channel structure, and the results show that the profits of the manufacturer and the overall supply chain increase under the dual-channel structure but the profits of the offline retailer decrease. In fact, customers may face different choices when a single or similar product is simultaneously sold in more than one retail channel, which leads to competition on multiple aspects. In this decentralized system, each channel tries to maximize its own profits in the presence of cannibalization, and channel conflicts caused by competition are inevitable [33, 41, 53, 54]. To resolve channel conflicts and mitigate the negative effects of competition, many papers in the literature have studied the mechanism of interchannel cooperation and coordination, including through cooperative pricing $[46,55,56]$, joint decisions [57-59], and coordination strategies [60, 61]. In addition, scholars have studied the pricing and replenishment strategies of the dual-channel supply chain system, the pricing- and delivery-time dependent stochastic demand, etc. For example, Panda et al. [62] considered that the unit cost of a product would be reduced during its short life cycle and discussed the pricing and replenishment policies of high-tech products in the dual-channel supply chain. The results showed that there was price competition between the retail channel and the online channel, and the channel conflict could be resolved through a profit sharing mechanism adjusted by wholesale price. Modak and Kelle [63] examined a dual-channel supply chain under price and delivery-time dependent stochastic customer demand and analysed the effect of delivery lead time and customers' channel preference on the optimal operation. The authors proposed a strategy to coordinate the supply chain by using a hybrid all-unit quantity discount of franchise fee contract. In contrast to the above studies on cooperation and coordination in the multistakeholder dual-channel structure, we study the product pricing and return strategies of a DCR as a single stakeholder when providing customers 
with return options. When a single retailer simultaneously operates two different channels (online and offline) and provides return services to customers, it will simultaneously face return requests from customers in different channels, and the workload and the cost of handing returns will increase significantly. In such a case, how should the DCR set prices for products in different channels? How should it choose the appropriate return strategy to maximize its profits? This is the main focus of our research and the problem it hopes to solve, and it also differs from the objectives of the above studies.

In a DCR setting, a retailer simultaneously sells similar products in a physical store and an online store. The DCR is the sole decision maker in the system and operates both the offline and online sales channels, and many studies have considered this kind of situation. Zhang [64] studied the pricing and advertising strategies of a retailer with multiple sales channels, and the results showed that compared with traditional single-channel retailing, advertising prices in multichannel retailing have different effects, helping to coordinate channels by transferring sales from online to offline. Yan [65] developed a game-theoretic model to determine the best brand strategy and market structure for a DCR. The results showed that for a DCR, the best brand strategy is to adopt as many brand differences as possible between the online and offline stores, especially when consumers are less price sensitive and the market base is larger. With an increasing number of retailers adopting dual channels, scholars have deeply investigated the decisionmaking issues facing DCRs from different perspectives, including competitive pricing [66-69], channel conflicts and coordination [70-72], and channel strategy [73-75]. In addition, some scholars have studied the business strategies of DCRs, such as the POPU (preorder-online, pickup-instore) strategy. Chatterjee [76] studied what types of consumers prefer the POPU strategy and indicated that highly frugal consumers are more inclined to purchase products through POPU. Gallino and Moreno [77] studied the impact of POPU on the online and offline sales of a DCR through empirical analysis and found that the implementation of this strategy can improve the sales and pedestrian volume of offline stores but has a negative impact on online sales. According to the survey results of Forrester Consulting's online white paper, although the POPU strategy is considered the most important channel integration strategy for DCRs, research on the POPU strategy remains sparse (Customer Desires Vs. Retailer Capabilities: Minding The Omni-Channel Commerce Gap, http://www.emarketingpapers.com/content47958/). What our research has in common with the above is that both are carried out in a DCR setting, but our work is significantly different from theirs. We focus on the impact of customer returns on the optimal pricing strategies and the retailer's choice of return strategy under the dual-channel business model, while the above studies did not consider returns. In fact, as we described in the Introduction, product returns are a part of the business process that cannot be ignored, and research on returns and other related issues arising from returns is of vital practical interest.

In the second stream of literature, i.e., which is on customer returns, a number of studies have reviewed refund policies. Chen and Chen [78] argued that refund policies are an important strategy for manufacturers and retailers to maintain market competitiveness and compete for customer service, and they developed a multioligopoly model to study the impact of refund policies on retailer pricing and profits. Suwelack et al. [10] pointed out that refund policy has cognitive, emotional, and behavioral outcomes that can reduce consumer risk perceptions, stimulate consumers' response to purchase emotions, and increase customers' willingness to purchase and pay. However, the key to these desirable outcomes is the design of the refund policy conditions. Most studies on refund policies have been carried out in the context of a single-retailer setting $[2,23,37]$ or a two-retailer setting $[8,29,30]$ and mainly focused on fullrefund, partial-refund, and no-refund policies. A few scholars have also studied consumer refund policies in the manufacturer-retailer dual-channel supply chain [79]. The single retailer mentioned here mainly refers to a retailer in a single-channel context (an offline physical retailer or an online retailer). Akçay et al. [2] studied a system in which consumer valuation is uncertain, but consumers can distinguish between new sales and resales, and the results showed that the retailer could reduce the number of returns by controlling sale prices and implementing a return policy. Chen and Bell [23] studied how to implement market segmentation using full-refund and no-refund consumer return policies and compared system performance under different refund policies. Chen and Chen [37] indicated that retailers should provide an MBG as long as the net salvage value of the returned product in a channel is positive. Studies on return policy in the context of the two retailers mainly focus on two competing retailers. McWilliams [8] explored the competitive environment between high- and low-quality retailers and studied the profitability of refund guarantees for two retailers with fully informed and risk-neutral consumers. Chen and Grewal [29] also conducted a study on two competitive retailers, and one of which has been well established and offers a full refund policy, while the other is a new entrant to the market and needs to decide whether to implement a full refund policy or no refund policy; their study proved that customer return policy can be used as a competitive marketing strategy. Balakrishnan et al. [30] combined the showrooming behavior of consumers with returns and studied return policy when consumers browse offline but purchase online and its impact on the profits of two online and offline retailers. Analyses of return policies under a single-channel retailer and two competing retailers mainly focus on the impact of customer returns on the retailer's pricing and profit and, based on this, whether a retailer should provide return services to customers and what kind of refund policy to adopt. DCRs operate both online and offline channels, and customers can choose either channel from which to purchase. However, when customers are not satisfied with a product, should they be allowed to return to whatever channel is most convenient for them? What choice should a DCR make in response to this kind of return request? Clearly, an analysis of a DCR's return policy needs to incorporate decisions on the return mode in addition to the abovementioned issues. 
In the existing literature on return policies, a few scholars have studied the return policies of a DCR, and even a fewer of them have simultaneously considered all return modes available to the DCR. Radhi and Zhang [39] studied crosschannel returns encountered by a DCR; their work addressed centralization under differential and unified pricing strategies and discussed the impact of customer preferences and return rates on dual-channel pricing, but they did not cover all possible return modes. Based on Radhi and Zhang [39], we consider all return modes available to the DCR, i.e., the original channel return mode, the fixed crosschannel return mode, and the relaxed cross-channel return mode. Moreover, in line with other arguments in the literature $[40,41]$, we believe that a fully coordinated or centralized monopoly system can use a single decision maker to maximize the total profit of the system. Therefore, we will study the optimal pricing strategies of channel products under the integrated decision-making mode for each return model. The work in this paper expands the literature on return theory in the dual-channel context and offers considerable assistance to the operation practice of DCRs.

\section{Problem Description}

To clarify the main part of the article, before discussing each return mode in detail, we first briefly explain the common assumptions and symbols involved in different return modes in the paper. This paper examines channel pricing and the selection of return mode when a DCR is considering accepting returns from customers if the retailer simultaneously operates both an offline physical store and an online store. According to different return modes, three return modes are discussed: original channel return, fixed crosschannel return, and relaxed cross-channel return. Under the original channel return mode, customers are allowed to return products only from the channel they purchased; under the fixed cross-channel return mode, no matter which channel customers purchase products from, they can return products only via the offline physical channel; the relaxed cross-channel return mode allows customers of an online channel to choose a return channel according to their wishes, but customers of an offline physical channel will not transfer to the online channel for return because the return using the offline physical channel is more convenient than that using the online channel. When customers return products due to product quality problems or for their own reasons but do not affect the resale of the products they have returned, customers can receive a full refund within the time specified by the retailer. Assume the return probability of the offline original channel is $r$, the return probability of the online original channel is $w$, the return probability of online cross-returned to offline is $v$, and $0 \leq r, w, v \leq 1$. The returns can be divided into two parts according to the status (quality, packaging, etc.) - resalable and nonresalable-and all resalable returns will be resold as new products, whereas nonresalable returns can be returned for only a certain salvage value. We assume that the probability of resalable returns from the offline original channel (or the proportion of the resalable part returned from the offline original channel) is $k_{r}$, the probability of resalable returns from the online original channel is $k_{o}$, the probability of resalable returns from online cross-returned to offline is $k_{o r}$, and $0 \leq k_{r}, k_{o}, k_{o r} \leq 1$. In addition, considering the feasibility and complexity of the model, we assume that the retailer can identify the status of the product (through the product ID), and the resalable parts cannot be sold and returned indefinitely. We define the part returned by the customer after the new products are sold as first returns, and the part that can be resold after first returns but then be returned once again after resales as second returns. No matter whether the second returns meet the resalable conditions or not, the produce will not be sold a third time, and only the salvage value will be processed. Assume the salvage value of the nonresalable part in the first returns and the second returns is $s$, the unit purchase cost is $c$, and $s \leq c$; otherwise, the DCR will always be profitable and lose the need for the decisionmaking process. In the process of collecting returns, no matter which channel the returns come from, there will be a collection cost $d$ for each unit of returns, and there will be additional freight cost $t$ for each unit of products sold and returned through the online channel.

Facing the DCRS strategy of the dual-channel retailer, customers have different preferences for purchasing channels and ultimately affect the potential market size of channels. If the parameter $\alpha$ is used to represent the total potential market size and $\theta(0 \leq \theta \leq 1)$ is used to represent the customer's preference for the offline channel, then $\alpha \theta$ represents the potential market size of the offline channel, denoted $\alpha_{r}=\alpha \theta$. In contrast, $\alpha(1-\theta)$ indicates the potential market size of the online channel, denoted $\alpha_{o}=\alpha(1-\theta)$. In addition, similar to many studies $[42,58,80,81]$, we adopt a linear market demand function in this paper; that is, the channel demand is a linear relationship of channel prices. Assume $\beta$ is the self-price sensitivity coefficient of the channel product $\gamma$ is the crossprice sensitivity coefficient of the products between channels, and $\beta>\gamma$; that is, the channel demand is more affected by the same channel price than by other channels. It should be noted that the above assumptions and the definition of symbols are applicable to all three return modes, but there are certain symbols, such as prices, demands, order quantities, and profits, that need to be distinguished in different return models. For clarity, the main assumptions involved in this paper are as follows, and the symbols used in this paper are summarized in Table 1.

Assumption 1. The share of first returns that are not resalable will be treated in terms of salvage value, but all second returns, regardless of whether they can be resold, will be treated in terms of salvage value.

Assumption 2. The DCR will generate a collection cost for each unit of return and bear the freight cost of the unit product in the sale and return links of the online channel.

Assumption 3. The self-price sensitivity coefficient of the channel product is greater than the cross-price sensitivity coefficient of the products between channels, that is, $\beta>\gamma$. 
TABLE 1: Symbols and corresponding descriptions.

\begin{tabular}{lr}
\hline Symbol & Description \\
\hline$r$ & Return probability of offline original channel $(0 \leq r \leq 1)$ \\
$w$ & Return probability of online original channel $(0 \leq w \leq 1)$ \\
$v$ & Return probability of online cross-returned to offline $(0 \leq v \leq 1)$ \\
$k_{r}$ & Probability of resalable offline original channel return \\
$k_{o}$ & Probability of resalable online original channel return \\
$k_{o r}$ & Probability of online purchase cross-returned offline and resalable \\
$c$ & Unit purchase cost \\
$d$ & Unit collection cost of returns \\
$t$ & Unit freight \\
$s$ & Salvage value $(s \leq c)$ \\
$\alpha$ & Potential market size \\
$\theta$ & Offline customer preference $(0 \leq \theta \leq 1)$ \\
$\alpha_{r}=\alpha \theta$ & Potential market size of offline channel \\
$\alpha_{o}=\alpha(1-\theta)$ & Potential market size of online channel \\
$\beta$ & Own-price sensitivity of a channel \\
$\gamma$ & Cross-price sensitivity of a channel \\
$i=o c, f c$ or $r c$ & Represents original channel return, fixed cross-channel return, and relaxed cross-channel return mode, respectively \\
$p_{r}^{i}$ and $p_{o}^{i}$ & Offline product price and online product price of return mode $i$ \\
$D_{r}^{i}$ and $D_{o}^{i}$ & Offline customer demand and online customer demand of return mode $i$ \\
$Q_{r}^{i}$ and $Q_{o}^{i}$ & Offline and online order quantities under return mode $i$ \\
$\pi_{r}^{i}$ and $\pi_{o}^{i}$ & Offline store profit and online store profit under return mode $i$ \\
$\pi^{i}$ & The total profit of the two channels of the DCR under return mode $i$ \\
\hline
\end{tabular}

\section{Original Channel Return Mode}

This section studies pricing policies of the original channel return mode, wherein customers who purchase products offline can return them only offline, while customers who purchase products online can return them only online. The original channel return mode is shown in Figure 1.

Since this paper does not consider the influence of complementary products on prices, the demand for a product is affected only by its own price and the price of the same product in another channel. Therefore, the market demands for the two channels are expressed as follows:

$$
\begin{aligned}
& D_{o}^{o c}=\alpha_{o}-\beta p_{o}^{o c}+\gamma p_{r}^{o c}, \\
& D_{r}^{o c}=\alpha_{r}-\beta p_{r}^{o c}+\gamma p_{o}^{o c},
\end{aligned}
$$

where $\beta$ is the own-price sensitivity, which reflects the degree to which channel demand is affected by a channel's own price, and $\gamma$ is the cross-price sensitivity, which reflects the degree of influence of prices between two channels on demand. A channel's cross-price sensitivity has a lesser effect on demand than a channel's own-price sensitivity, that is, $\beta>\gamma \cdot \beta p_{o}^{o c}$ represents the decrease in online sales due to the impact of the online price; $\gamma p_{r}^{o c}$ represents the increase in online sales due to the impact of the price of the same product offline. Similarly, $\beta p_{r}^{o c}$ represents the decrease in offline sales due to the impact of the offline price; $\gamma p_{o}^{o c}$ indicates the increase in offline sales due to the effect of the price of the same product online.

On the other hand, as the DCR accepts customer returns, the resalable part of first returns can be used to meet the needs of customers; that is to say, the market demand of the channel is jointly met by the order quantity of the channel and the resalable part of first returns. Therefore, the demand

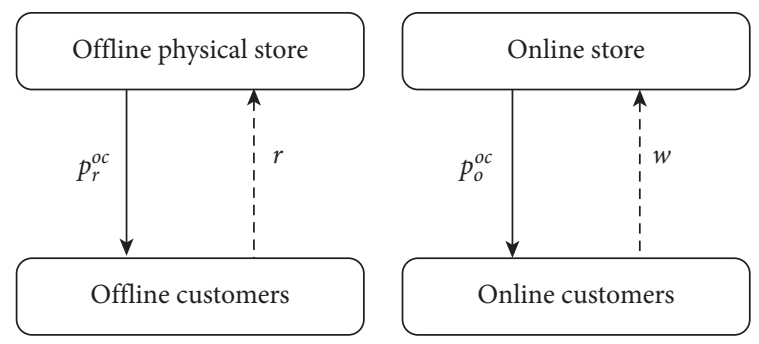

FIGURE 1: Original channel return mode.

functions can be expressed by the order quantities. Specifically, the online demand is composed of the online order quantity and the first returned but resalable share of the online channel, and the offline demand is composed of the offline order quantity and the first returned but resalable share of the offline channel. Thus, the online and offline demand functions are modeled as follows:

$$
\begin{aligned}
& D_{o}^{o c}=Q_{o}^{o c}+w k_{o} Q_{o}^{o c}, \\
& D_{r}^{o c}=Q_{r}^{o c}+r k_{r} Q_{r}^{o c},
\end{aligned}
$$

where $w k_{o} Q_{o}^{o c}$ represents the resalable returns of the online channel and $r k_{r} Q_{r}^{o c}$ represents the resalable returns of the offline channel.

From formulas (3) and (4), the online and offline order quantities are given as

$$
\begin{aligned}
& Q_{o}^{o c}=\frac{D_{o}^{o c}}{\left(1+w k_{o}\right)}, \\
& Q_{r}^{o c}=\frac{D_{r}^{o c}}{\left(1+r k_{r}\right)} .
\end{aligned}
$$


In the original channel return mode, there are no crosschannel returns, so $v=0$, and the profit function involves six parts: total sales, cost of returns collection, freight (only for online channel sales and its returns), salvage value for first returns that are nonresalable, salvage value for second returns, and product ordering cost. Therefore, the profit functions of the online and offline channels are given as

$$
\begin{aligned}
\pi_{o}^{o c}= & D_{o}^{o c}\left[(1-w) p_{o}^{o c}-t-(d+t) w+s w\left(1-k_{o}\right)\right] \\
& +s Q_{o}^{o c} w^{2} k_{o}^{2}-c Q_{o}^{o c},
\end{aligned}
$$

$$
\pi_{r}^{o c}=D_{r}^{o c}\left[(1-r) p_{r}^{o c}-r d+s r\left(1-k_{r}\right)\right]+s Q_{r}^{o c} r^{2} k_{r}^{2}-c Q_{r}^{o c} .
$$

In formula (7), $(1-w) p_{o}^{o c} D_{o}^{o c}$ is the total revenue from online sales, that is, the total revenue from the products actually sold through the online channel (including the first and second sales of products that have not been returned); $D_{o}^{o c} t$ is the freight cost for online channel sales; $(d+t) w D_{o}^{o c}$ is the collection and shipping cost incurred for returns in the online channel; $s w\left(1-k_{o}\right) D_{o}^{o c}$ is the salvage value of the nonresalable share returned from the online channel (including the nonresalable share of first and the second returns); $s Q_{o}^{o c} w^{2} k_{o}^{2}$ is the salvage value of the resalable share of second returns from the online channel; and $c Q_{o}^{o c}$ is the ordering cost in the online channel. Similarly, in (8), $(1-r) p_{r}^{o c} D_{r}^{o c}$ is the total revenue from products actually sold through the offline channel; $r d D_{r}^{o c}$ is the collection cost incurred for returns in offline channel; $s r\left(1-k_{r}\right) D_{r}^{o c}$ is the salvage value of the nonresalable share of returns from the offline channel; $s Q_{r}^{o c} r^{2} k_{r}^{2}$ is the salvage value of the resalable share of second returns from the offline channel; and $c Q_{r}^{o c}$ is the ordering cost of the online channel.

From formulas (7) and (8), the total profit of the DCR is modeled as

$$
\begin{aligned}
\pi^{o c}= & \pi_{o}^{o c}+\pi_{r}^{o c}=D_{o}^{o c}\left[(1-w) p_{o}^{o c}-t-(d+t) w+s w\left(1-k_{o}\right)\right] \\
& +s Q_{o}^{o c} w^{2} k_{o}^{2}-c Q_{o}^{o c} \\
& +D_{r}^{o c}\left[(1-r) p_{r}^{o c}-r d+s r\left(1-k_{r}\right)\right]+s Q_{r}^{o c} r^{2} k_{r}^{2}-c Q_{r}^{o c} .
\end{aligned}
$$

Substituting equations (5) and (6) into equation (9), the total profit of the DCR can be transformed into the following:

$$
\begin{aligned}
\pi^{o c}= & \pi_{o}^{o c}+\pi_{r}^{o c}=D_{o}^{o c}\left[(1-w) p_{o}^{o c}-t-(d+t) w+s w\left(1-k_{o}\right)+\frac{\left(s w^{2} k_{o}^{2}-c\right)}{\left(1+w k_{o}\right)}\right] \\
& +D_{r}^{o c}\left[(1-r) p_{r}^{o c}-r d+s r\left(1-k_{r}\right)+\frac{\left(s r^{2} k_{r}^{2}-c\right)}{\left(1+r k_{r}\right)}\right] .
\end{aligned}
$$

Let $A=r d-s r\left(1-k_{r}\right)-\left(s r^{2} k_{r}^{2}-c\right) /\left(1+r k_{r}\right), I=(1-$ $r)>0$, and $J=(1-w-v)>0$ (note that $v=0$ under the original channel return mode, and define $\left.J^{o c}=(1-w)>0\right)$ and $B=t+(d+t) w-s w\left(1-k_{o}\right)-\left(s w^{2} k_{o}^{2}-c\right) /\left(1+w k_{o}\right)$. Then, the profit function can be reformulated as

$$
\pi^{o c}=D_{o}^{o c}\left[J^{o c} p_{o}^{o c}-B\right]+D_{r}^{o c}\left[I p_{r}^{o c}-A\right] .
$$

Proposition 1. Under the original channel return mode, the profit function $\pi^{o c}$ of the DCR is strictly and jointly concave in $p_{o}^{o c}$ and $p_{r}^{o c}$, when $4 I J^{o c} \beta^{2}-\left(I+J^{o c}\right)^{2} \gamma^{2}>0$ is satisfied, and the optimal prices of the online and offline channels are as follows:

$$
\begin{aligned}
& p_{o}^{o c *}=\frac{\gamma\left(I \alpha_{r}-B \gamma\right)\left(I+J^{o c}\right)+\beta A \gamma\left(J^{o c}-I\right)+2 I \beta\left(J^{o c} \alpha_{o}+B \beta\right)}{4 I J^{o c} \beta^{2}-\left(I+J^{o c}\right)^{2} \gamma^{2}}, \\
& p_{r}^{o c *}=\frac{\gamma\left(J^{o c} \alpha_{o}-A \gamma\right)\left(I+J^{o c}\right)+\beta B \gamma\left(I-J^{o c}\right)+2 J^{o c} \beta\left(I \alpha_{r}+A \beta\right)}{4 I J^{o c} \beta^{2}-\left(I+J^{o c}\right)^{2} \gamma^{2}} .
\end{aligned}
$$

Proof. By substituting demand functions (1) and (2) into the profit function of the DCR under this return mode $\pi^{o c}$, i.e., (11), one can construct the Hessian matrix of the profit function $\pi^{o c}$ for channel prices $p_{o}^{o c}$ and $p_{r}^{o c}$ as follows:

$$
H^{o c}=\left(\begin{array}{cc}
\frac{\partial^{2} \pi^{o c}}{\partial p_{o}^{o c 2}} & \frac{\partial^{2} \pi^{o c}}{\partial p_{o}^{o c} \partial p_{r}^{o c}} \\
\frac{\partial^{2} \pi^{o c}}{\partial p_{r}^{o c} \partial p_{o}^{o c}} & \frac{\partial^{2} \pi^{o c}}{\partial p_{r}^{o c 2}}
\end{array}\right)=\left(\begin{array}{cc}
-2 J^{o c} \beta & \left(I+J^{o c}\right) \gamma \\
\left(I+J^{o c}\right) \gamma & -2 I \beta
\end{array}\right) .
$$

Because $\partial^{2} \pi^{o c} / \partial p_{o}^{o c 2}<0$, the Hesse matrix is negative definite given that $\left|H^{o c}\right|=4 I J^{o c} \beta^{2}-\left(I+J^{o c}\right)^{2} \gamma^{2}>0$. The profit function of the DCR is strictly and jointly concave in $p_{o}^{o c}$ and $p_{r}^{o c}$, and there is a unique optimal set of prices. By simultaneously solving the first-order conditions $\partial \pi^{o c} / \partial p_{o}^{o c}=0$ and $\partial \pi^{o c} / \partial p_{r}^{o c}=0$, the optimal prices $p_{o}^{o c *}$ and $p_{r}^{o c *}$ can be obtained.

From Proposition 1, we know that the prerequisite for the DCR to obtain the above optimal prices is $4 I J^{o c} \beta^{2}-\left(I+J^{o c}\right)^{2} \gamma^{2}>0$. However, this condition may not always be satisfied. Although we assume that the own-price sensitivity of a channel $\beta$ and the cross-channel price sensitivity $\gamma$ satisfy $\beta>\gamma, 4 I J^{o c}-\left(I+J^{o c}\right)^{2} \leq 0$ due to $I=(1-$ $r)>0$ and $J^{o c}=(1-w)>0$, which means that inequality $4 I J^{o c} \beta^{2}-\left(I+J^{o c}\right)^{2} \gamma^{2}>0$ may not be satisfied, especially when $\beta$ is very close to $\gamma$ or the difference between $I$ and $J^{o c}$ is large. However, those cases are less likely to occur. On the one hand, the own-price sensitivity of the channel $\beta$ tends to 
be significantly larger than the cross-channel price sensitivity $\gamma$; on the other hand, the difference between $I$ and $J^{o c}$ is extremely large, indicating that the return rate of one channel is significantly greater than that of the other channel. No retailer will tolerate a channel with an excessive return rate for a long time; the return policy will either be cancelled, or the retailer will adopt the appropriate strategies to reduce the return rate, which indirectly indicates that Iand $J^{o c}$ should be closer. Therefore, $4 I J^{o c} \beta^{2}-\left(I+J^{o c}\right)^{2} \gamma^{2}>0$ can be satisfied in most cases, which ensures the existence of optimal prices for a DCR.

Based on Proposition 1, Lemma 1 can be obtained by analysing the differentials of optimal prices $p_{o}^{o c *}$ and $p_{r}^{o c *}$ with respect to $\theta$.

Lemma 1. Under the original channel return mode, the optimal channel pricing of the DCR will increase with the increase of their channel preference.

Proof. According to Proposition 1, the optimal pricing $p_{o}^{o c *}$ and $p_{r}^{o c *}$ of the DCR should satisfy $\partial \pi^{o c} / \partial p_{o}^{o c}=0$ and $\partial \pi^{o c} / \partial p_{r}^{o c}=0$; that is,

$$
\left\{\begin{array}{l}
\frac{\partial \pi^{o c}}{\partial p_{o}^{o c}}\left(p_{o}^{o c *}\right)=\left[(1-\theta) \alpha-\beta p_{o}^{o c *}+\gamma p_{r}^{o c *}\right] J^{o c} \\
-\beta\left(J^{o c} p_{o}^{o c *}-B\right)+\gamma\left(I p_{r}^{o c *}-A\right)=0, \\
\frac{\partial \pi^{o c}}{\partial p_{r}^{o c}}\left(p_{r}^{o c *}\right)=\left[\theta \alpha-\beta p_{r}^{o c *}+\gamma p_{o}^{o c *}\right] I-\beta\left(I p_{r}^{o c *}-A\right) \\
\quad+\gamma\left(J^{o c} p_{o}^{o c *}-B\right)=0 .
\end{array}\right.
$$

Considering the above two equations as implicit functions of optimal pricing $p_{o}^{o c *}$ and $p_{r}^{o c *}$ with respect to $\theta$, respectively, by simultaneously solving the first-order conditions with respect to $\theta$, one can obtain

$$
\left\{\begin{array}{l}
\left(-\alpha-\beta \frac{\partial p_{o}^{o c *}}{\partial \theta}+\gamma \frac{\partial p_{r}^{o c *}}{\partial \theta}\right) J^{o c}-J^{o c} \beta \frac{\partial p_{o}^{o c *}}{\partial \theta}+I \gamma \frac{\partial p_{r}^{o c *}}{\theta}=0, \\
\left(\alpha-\beta \frac{\partial p_{r}^{o c *}}{\partial \theta}+\gamma \frac{\partial p_{o}^{o c *}}{\partial \theta}\right) I-I \beta \frac{\partial p_{r}^{o c *}}{\partial \theta}+J^{o c} \gamma \frac{\partial p_{o}^{o c *}}{\partial \theta}=0 .
\end{array}\right.
$$

By solving the above equations, we can obtain $\partial p_{o}^{o c *}$ $/ \partial \theta=\left(\left(\alpha I\left[\gamma\left(I+J^{o c}\right)-2 J^{o c} \beta\right]\right) /\left(4 I J^{o c} \beta^{2}-\left(I+J^{o c}\right)^{2} \quad \gamma^{2}\right)\right)$, $\partial p_{r}^{o c *} \quad / \partial \theta=\left(\left(\alpha J^{o c}\left[2 I \beta-\gamma\left(I+J^{o c}\right)\right]\right) /\left(4 I J^{o c} \beta^{2}-\left(I+J^{o c}\right)^{2}\right.\right.$ $\left.\left.\gamma^{2}\right)\right)$. According to the same reasoning used for the existence of optimal prices for a DCR described above, as the ownprice sensitivity of channel $\beta$ tends to be significantly larger than the cross-channel price sensitivity $\gamma$, and the difference between $I$ and $J^{o c}$ is small, we can find $\left(\partial p_{r}^{o c *} / \partial \theta\right)>0$ and $\left(\partial p_{o}^{o c *} / \partial \theta\right)<0$, indicating that the optimal pricing of the offline channel will increase with the increases in its channel preference $\theta$, while the optimal pricing of the online channel will decrease as $\theta$ increases. This also means that the optimal pricing of the online channel will increase with the increases in online channel preference $1-\theta$. Thus, Lemma 1 is proven.

Proposition 1 shows that the optimal channel pricing of the DCR depends on the following parameters-price sensitivity coefficients $(\beta, \gamma)$, offline channel preference $(\theta)$, return rates of original channel $(r, w)$, probabilities of resalable $\left(k_{r}, k_{o}\right)$, and salvage value $(s)$-and the values of these parameters are generally exogenous. Some parameters can be obtained through statistical investigation, such as probabilities of return and resalable, while the salvage value depends on the negotiation ability of the DCR. Once the values of these exogenous parameters are determined, the DCR can use the pricing formulas in Proposition 1 to set the optimal channel prices. Lemma 1 shows that, as long as the difference in return rate between channels is not significant, the DCR should set a higher retail price for the channel with high customer channel preference under the same conditions in order to obtain higher system profits.

\section{Fixed Cross-Channel Return Mode}

The fixed cross-channel return mode refers to customers making returns through offline or online channels designated by the retailer and is commonly employed in practice. For example, Amazon, an e-commerce giant, chose to cooperate with Kohl's (a chain of family-oriented professional department stores in the United States) to simplify the return process; this approach has been a success: starting with the ability to make returns at only 100 Kohl's stores, customers can now return multiple items purchased from Amazon to any Kohl's store. Many practical examples show that most customers prefer to return through offline channels rather than returning online. David Cobie, co-founder and CEO of Happy Returns, said that in general, customers go to physical stores to return goods in person and receive refunds faster, which seems to be the most attractive approach for customers. Therefore, in this section, we study the situation where the customer can return items only through an offline channel, regardless of whether he/she purchased the item online or offline, and the customer will receive a full refund on any purchased item returned within the specified time period.

In this section, we again consider a monopolized DCR as the sole decision maker in the system. To facilitate the expression of the model, some assumptions similar to those of Section 3 are retained. The fixed cross-channel return mode is shown in Figure 2.

In the fixed cross-channel return mode, the online channel does not accept returns, so there are no secondary sales, and the demand in the online channel is equal to its order quantity. However, the offline channel will receive returns from both online and offline channels, some of which can be resold. Therefore, the demand in the offline channel is composed of the initial order quantity of the offline channel, the share of first returns that are resalable from the offline channel and those from the online channel cross-returned to the offline channel. The demand functions of the online channel and offline channel are given as 


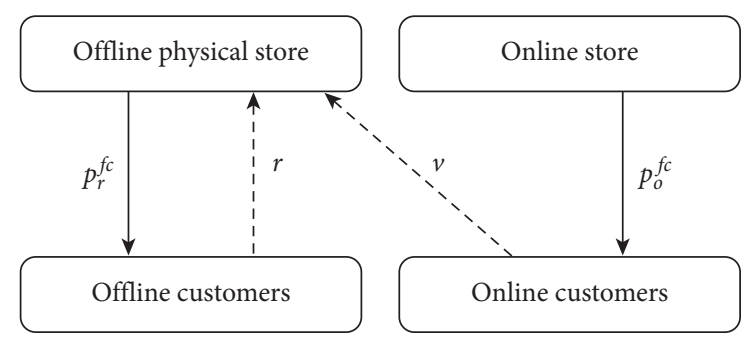

Figure 2: Fixed cross-channel return mode.

$$
\begin{aligned}
& D_{o}^{f c}=Q_{o}^{f c}, \\
& D_{r}^{f c}=Q_{r}^{f c}+r k_{r} Q_{r}^{f c}+v k_{o r} Q_{r}^{f c},
\end{aligned}
$$

where $v k_{o r} Q_{o}^{f c}$ represents the resalable returns purchased from the online channel and cross-returned to the offline channel. The other terms are defined the same meaning as in the original channel return mode.

According to (16) and (17), the order quantities of the online channel and offline channel are given as

$$
\begin{aligned}
& Q_{o}^{f c}=D_{o}^{f c}, \\
& Q_{r}^{f c}=\left(D_{r}^{f c}-v k_{o r} Q_{o}^{f c}\right) /\left(1+r k_{r}\right) .
\end{aligned}
$$

In the fixed cross-channel return mode, there are no online channel returns, which means that $w=0$. The profit function of the fixed cross-channel return mode involves six parts: total sales, cost of return collection, freight (only online channel sales), the salvage value of nonresalable first returns, the salvage value of second returns, and the product ordering cost. The profit functions of the online and offline channels are as follows:

$$
\begin{aligned}
\pi_{o}^{f c} & =D_{o}^{f c}\left[(1-v) p_{o}^{f c}-t\right]-c Q_{o}^{f c}, \\
\pi_{r}^{f c}= & D_{r}^{f c}\left[(1-r) p_{r}^{f c}-r d+s r\left(1-k_{r}\right)\right] \\
& +s Q_{r}^{f c} r^{2} k_{r}^{2}+s Q_{o}^{f c} k_{o r} k_{r} v r \\
& +D_{o}^{f c}\left[-v d+s v\left(1-k_{o r}\right)\right]-c Q_{r}^{f c} .
\end{aligned}
$$

In (20), $(1-v) p_{o}^{f c} D_{o}^{f c}$ is the total revenue from online sales, which makes a positive contribution to the profit of the DCR's online channel; $D_{o}^{f c} t$ is the freight expense incurred for online channel sales, which has a negative impact on profit, and $c Q_{o}^{f c}$ is the ordering cost of the online channel. In (21), $D_{r}^{f c}(1-r) p_{r}^{f c}$ is the total revenue from offline sales; $s r\left(1-k_{r}\right) D_{r}^{f c}$ represents the salvage value of all nonresalable returns from the offline channel, including the nonsalable shares of both the first and the second returns from the offline channel and the nonsalable share of the second returns, which belongs to the resalable share of the first cross-returns from the online channel to the offline channel; $s Q_{r}^{f c} r^{2} k_{r}^{2}$ and $s Q_{o}^{f c} k_{o r} k_{r} v r$ are the salvage values of the resalable shares of the second returns from the offline channel and the second returns derived from the resalable share of the first cross-returns from the online to the offline channel, respectively, and $D_{o}^{f c} s v\left(1-k_{o r}\right)$ is the salvage value of the nonresalable share of second cross-returns. The above five parts all have a positive impact on the profit of the offline channel of the DCR. In contrast, $D_{r}^{f c} r d$ is the collection cost of the offline channel, $D_{o}^{f c} v d$ is the collection cost of the retailer from handling the online cross-returns, and $c Q_{r}^{f c}$ is the ordering cost of the offline channel. These three items obviously have a negative impact on the profit function of the offline channel.

From (20) and (21), the total profit of the DCR is modeled as follows:

$$
\begin{aligned}
\pi^{f c}= & \pi_{o}^{f c}+\pi_{r}^{f c}=D_{o}^{f c}\left[(1-v) p_{o}^{f c}-t\right]-c Q_{o}^{f c} \\
& +D_{r}^{f c}\left[(1-r) p_{r}^{f c}-r d+s r\left(1-k_{r}\right)\right] \\
& +s Q_{r}^{f c} r^{2} k_{r}^{2}+s Q_{o}^{f c} k_{o r} k_{r} v r \\
& +D_{o}^{f c}\left[-v d+s v\left(1-k_{o r}\right)\right]-c Q_{r}^{f c} .
\end{aligned}
$$

Substituting (18) and (19) into (23), the total profit of the DCR can be transformed as follows:

$$
\begin{aligned}
\pi^{f c}= & \pi_{o}^{f c}+\pi_{r}^{f c} \\
= & D_{o}^{f c}\left[(1-v) p_{o}^{f c}-t-c+s k_{o r} k_{r} v r-v d+s v\left(1-k_{o r}\right)\right. \\
& \left.+\frac{v k_{o r}\left(c-s k_{r}^{2} r^{2}\right)}{1+r k_{r}}\right] \\
& +D_{r}^{f c}\left[(1-r) p_{r}^{f c}-r d+s r\left(1-k_{r}\right)+\frac{s r^{2} k_{r}^{2}-c}{1+r k_{r}}\right] .
\end{aligned}
$$

Let $E=r d-s r\left(1-k_{r}\right)-\left(\left(s r^{2} k_{r}^{2}-c\right) /\left(1+r k_{r}\right)\right), \quad I=$ $(1-r)>0$, and $J=(1-w-v)>0$ (note that $w=0$ under the fixed cross-channel return mode, and define $J^{f c}=$ $(1-v)>0)$ and $F=t+c-s k_{o r} k_{r} v r+v d-s v\left(1-k_{o r}\right)-$ $\left(\left(v k_{o r}\left(c-s k_{r}^{2} r^{2}\right)\right) /\left(1+r k_{r}\right)\right)$. Then, the profit function can be reformulated as follows:

$$
\pi^{f c}=D_{o}^{f c}\left[J^{f c} p_{o}^{f c}-F\right]+D_{r}^{f c}\left[I p_{r}^{f c}-E\right]
$$

Proposition 2. Under the fixed cross-channel return mode, the profit function $\pi^{f c}$ of the DCR is strictly and jointly concave in $p_{o}^{f c}$ and $p_{r}^{f c}$, when $4 I J^{f c} \beta^{2}-\left(I+J^{f c}\right)^{2} \gamma^{2}>0$ is satisfied, and the optimal prices of online and offline channels are as follows:

$$
\begin{aligned}
& p_{o}^{f c *}=\frac{\gamma\left(I \alpha_{r}-F \gamma\right)\left(I+J^{f c}\right)+\beta E \gamma\left(J^{f c}-I\right)+2 I \beta\left(J^{f c} \alpha_{o}+F \beta\right)}{4 I J^{f c} \beta^{2}-\left(I+J^{f c}\right)^{2} \gamma^{2}}, \\
& p_{r}^{f c *}=\frac{\gamma\left(J^{f c} \alpha_{o}-E \gamma\right)\left(I+J^{f c}\right)+\beta F \gamma\left(J^{f c}-I\right)+2 J^{f c} \beta\left(I \alpha_{r}+E \beta\right)}{4 I J^{f c} \beta^{2}-\left(I+J^{f c}\right)^{2} \gamma^{2}} .
\end{aligned}
$$

Proof. Omitted due to its similarity to the proof of Proposition 1.

Here, we encounter a situation similar to Proposition 1, where the prerequisite for the DCR to obtain the above 
optimal pricing remains $4 I J^{f c} \beta^{2}-\left(I+J^{f c}\right)^{2} \gamma^{2}>0$. Although $J^{f c}=(1-v)>0 \quad(w=0)$ here is different from $J^{o c}=(1-w)>0(v=0)$ in Proposition 1, the reason that makes the inequality $4 I J^{f c} \beta^{2}-\left(I+J^{f c}\right)^{2} \gamma^{2}>0$ hold is the same, so we will not explain it redundantly here. That is, the inequality $4 I J^{f c} \beta^{2}-\left(I+J^{f c}\right)^{2} \gamma^{2}>0$ still holds most of the time, which guarantees the existence of optimal pricing for the DCR. By analysing the differentials of optimal prices $p_{o}^{f c *}$ and $p_{r}^{f c *}$ with respect to $\theta$, Lemma 2 can be obtained.

Lemma 2. Under the fixed cross-channel return mode, the optimal channel pricing of the DCR will increase with the increase in their channel preference.

Proof. Omitted due to its similarity to the proof of Lemma 1.

As with Proposition 1 in Section 4, Proposition 2 also shows that the optimal channel prices of the DCR depend on the value of other parameters, the difference is that there is no online original channel return in the fixed cross-channel mode, so the online original channel return rate $w$ is replaced by the cross-channel return rate $v$. Similarly, once the values of these exogenous parameters are determined, the DCR can use the pricing formulas in Proposition 2 to set the optimal channel prices under the fixed cross-channel return mode. The conclusion of Lemma 2 is similar to that of Lemma 1, which still shows that a DCR should set a higher retail price for the channel with high customer channel preference to obtain higher system profit.

\section{Relaxed Cross-Channel Return Mode}

In contrast to the original channel return mode and the fixed cross-channel return mode, the relaxed cross-channel return mode allows customers to freely choose the channel to use to return products purchased through the online channel. That is, customers can return the products purchased online through the same channel, or they can choose to return these products to a nearby physical location of the offline channel. It is important for customers to have a convenient choice in the return process because such a policy can not only increase sales but also help to improve customer satisfaction and cultivate customer loyalty. For example, to catch up with Amazon's e-commerce service, Wal-Mart has set up a "quick return channel" in most of its stores in the United States to take advantage of its multiple offline stores, and customers who purchase at Walmart.com and need to return products can complete the return process by simply using their mobile phones and receiving a refund immediately. Of course, customers can also choose to return products through the online channel by mail. In fact, a growing number of companies are beginning to focus on channel integration strategies to gain competitive advantage, which further illustrates the practical value of return mode research.

The assumptions required for the model in this section are the same as those in Section 3, so we do not repeat them here. A schematic diagram of the relaxed cross-channel return mode is shown in Figure 3.
Under the relaxed cross-channel return mode, the demand in the online channel is identical in form to that of the original channel return mode, consisting of the order quantity in the online channel and the resalable share of first returns in the online channel. The form of offline channel demand is the same as that of the fixed cross-channel return mode, consisting of offline order quantity, the resalable share of first returns from the offline channel, and the resalable share of cross-returns. Thus, the demand functions of the online channel and offline channel can be expressed as

$$
\begin{aligned}
& D_{o}^{r c}=Q_{o}^{r c}+w k_{o} Q_{o}^{r c}, \\
& D_{r}^{r c}=Q_{r}^{r c}+r k_{r} Q_{r}^{r c}+v k_{o r} Q_{o}^{r c} .
\end{aligned}
$$

From (27) and (28), we can obtain the relationship between the order quantity and the demand of the DCR's online and offline channels as follows:

$$
\begin{aligned}
Q_{o}^{r c} & =\frac{D_{o}^{r c}}{\left(1+w k_{o}\right)}, \\
Q_{r}^{r c} & =\frac{\left(D_{r}^{r c}-v Q_{o}^{r c} k_{o r}\right)}{\left(1+r k_{r}\right)} .
\end{aligned}
$$

The profit function of the relaxed cross-channel return mode also involves six aspects: total sales, cost of return collection, freight (only for online channel sales and returns), the salvage value for first returns that are nonresalable, the salvage value for second returns, and the product ordering cost. Therefore, the profit functions of the online channel and offline channel are as follows:

$$
\begin{aligned}
\pi_{o}^{r c}= & D_{o}^{r c}\left[(1-w-v) p_{o}^{r c}-t-(d+t) w+s w\left(1-k_{o}\right)\right] \\
& +s Q_{o}^{r c} w^{2} k_{o}^{2}-c Q_{o}^{r c}, \\
\pi_{r}^{r c}= & D_{r}^{r c}\left[(1-r) p_{r}^{r c}-r d+s r\left(1-k_{r}\right)\right] \\
& +s Q_{r}^{r c} r^{2} k_{r}^{2}+s Q_{o}^{r c} k_{o r} k_{r} v r \\
& +D_{o}^{r c}\left[-v d+s v\left(1-k_{o r}\right)\right]+s Q_{o}^{r c} k_{o} k_{o r} w v-c Q_{r}^{r c} .
\end{aligned}
$$

In (29), $(1-w-v) p_{o}^{r c} D_{o}^{r c}$ is the total revenue from online sales, that is, the total revenue from products actually sold through the online channel; $D_{o}^{r c} t$ is the freight cost for online channel sales; $(d+t) w D_{o}^{r c}$ represents the collection and freight costs incurred for returns through the online channel; $s w\left(1-k_{o}\right) D_{o}^{r c}$ is the salvage value of the nonresalable share of returns from the online channel (including the nonresalable share of the first returns and the second returns); $s Q_{o}^{r c} w^{2} k_{o}^{2}$ is the salvage value of the resalable share of second returns from the online channel, and $c Q_{o}^{r c}$ is the ordering cost of the online channel. In (30), $(1-r) p_{r}^{r c} D_{r}^{r c}$ is the total revenue of products actually sold through the offline channel; $r d D_{r}^{r c}$ is the collection cost incurred for the returns through the offline channel; $s r\left(1-k_{r}\right) D_{r}^{r c}$ is the salvage value of the nonresalable share of returns from the offline channel (including the nonresalable share of the first returns and the second returns); $s Q_{r}^{r c} r^{2} k_{r}^{2}$ is the salvage value of the resalable share of the second returns from the offline channel; $s Q_{o}^{r c} k_{o r} k_{r} v r$ represents the salvage value of the resalable share of the second returns, which derive from the 


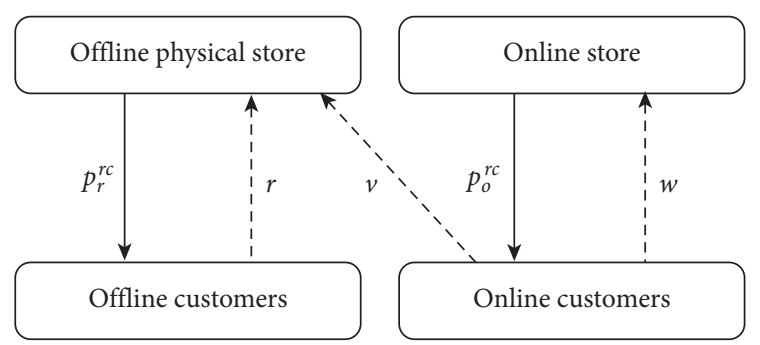

FIgURE 3: Relaxed cross-channel return mode.

resalable share of first cross-returns from the online channel to the offline channel; $D_{o}^{r c} v d$ is the collection cost incurred by the retailer to handle online cross-returns; $s v\left(1-k_{o r}\right) D_{o}^{r c}$ is the salvage value of the nonresalable share of second crossreturns from the online to the offline channel; $s Q_{o}^{r c} k_{o} k_{o r} w v$ is the salvage value of the resalable share of the second crossreturns from the online to the offline channel, which derives from the resalable share of first returns from the online channel, and $c Q_{r}^{r c}$ is the ordering cost for the offline channel.

From equations (29) and (30), the total profit of the DCR is modeled as

$$
\begin{aligned}
\pi^{r c}= & \pi_{o}^{r c}+\pi_{r}^{r c}=D_{o}^{r c}\left[(1-w-v) p_{o}^{r c}-t-(d+t) w\right. \\
& \left.+s w\left(1-k_{o}\right)\right]+s Q_{o}^{r c} w^{2} k_{o}^{2}-c Q_{o}^{r c} \\
& +D_{r}^{r c}\left[(1-r) p_{r}^{r c}-r d+s r\left(1-k_{r}\right)\right] \\
& +s Q_{r}^{r c} r^{2} k_{r}^{2}+s Q_{o}^{r c} k_{o r} k_{r} v r \\
& +D_{o}^{r c}\left[-v d+s v\left(1-k_{o r}\right)\right]+s Q_{o}^{r c} k_{o} k_{o r} w v-c Q_{r}^{r c} .
\end{aligned}
$$

Substituting equations (27) and (28) into (31), the total profit of the DCR can be transformed as follows:

$$
\begin{aligned}
\pi^{r c}= & \pi_{o}^{r c}+\pi_{r}^{r c}=D_{o}^{r c}\left[(1-w-v) p_{o}^{r c}-t-(d+t) w\right. \\
& +s w\left(1-k_{o}\right)-v d+s v\left(1-k_{o r}\right) \\
& \left.+\frac{s\left(v r k_{o r} k_{r}+w v k_{o r} k_{o}+w^{2} k_{o}^{2}\right)-c}{1+w k_{o}}+\frac{v k_{o r}\left(c-s k_{r}^{2} r^{2}\right)}{\left(1+r k_{r}\right)\left(1+w k_{o}\right)}\right] \\
& +D_{r}^{r c}\left[(1-r) p_{r}^{r c}-r d+s r\left(1-k_{r}\right)+\frac{s r^{2} k_{r}^{2}-c}{1+r k_{r}}\right] .
\end{aligned}
$$

Let $M=r d-s r\left(1-k_{r}\right)-\left(\left(s r^{2} k_{r}^{2}-c\right) /\left(1+r k_{r}\right)\right), \quad I=$ $(1-r)>0, J^{r c}=(1-w-v)>0$,

$$
\begin{aligned}
N= & t+(d+t) w-s w\left(1-k_{o}\right)+v d-s v\left(1-k_{o r}\right) \\
& -\frac{s\left(v r k_{o r} k_{r}+w v k_{o r} k_{o}+w^{2} k_{o}^{2}\right)-c}{1+w k_{o}} \\
& -\frac{v k_{o r}\left(c-s k_{r}^{2} r^{2}\right)}{\left(1+r k_{r}\right)\left(1+w k_{o}\right)}
\end{aligned}
$$

Then, the profit function can be reformulated as

$$
\pi^{r c}=D_{o}^{r c}\left[J^{r c} p_{o}^{r c}-N\right]+D_{r}^{r c}\left[I p_{r}^{r c}-M\right] .
$$

Proposition 3. Under the relaxed cross-channel return mode, the profit function $\pi^{r c}$ of the DCR is strictly and jointly concave in $p_{o}^{r c}$ and $p_{r}^{r c}$ when $4 I J^{r c} \beta^{2}-\left(I+J^{r c}\right)^{2} \gamma^{2}>0$ is satisfied, and the optimal prices of the online and offline channels are as follows:

$$
\begin{aligned}
& p_{o}^{r c *}=\frac{\gamma\left(I \alpha_{r}-N \gamma\right)\left(I+J^{r c}\right)+\beta M \gamma\left(J^{r c}-I\right)+2 I \beta\left(J^{r c} \alpha_{o}+N \beta\right)}{4 I J^{r c} \beta^{2}-\left(I+J^{r c}\right)^{2} \gamma^{2}}, \\
& p_{r}^{r c *}=\frac{\gamma\left(J^{r c} \alpha_{o}-M \gamma\right)\left(I+J^{r c}\right)+\beta N \gamma\left(J^{r c}-I\right)+2 J^{r c} \beta\left(I \alpha_{r}+M \beta\right)}{4 I J^{r c} \beta^{2}-\left(I+J^{r c}\right)^{2} \gamma^{2}} .
\end{aligned}
$$

Proof. Omitted due to the similarity to proof of Proposition 1. Similar to Propositions 1 and 2, the prerequisite for the DCR to obtain the above optimal pricing remains $4 I J^{r c} \beta^{2}-\left(I+J^{r c}\right)^{2} \gamma^{2}>0$. Note that under the relaxed crosschannel return mode, $J^{r c}=(1-w-v)>0$, and it is no longer required that $v=0$ or $w=0$. However, for the same reason, we believe that the inequality $4 I J^{r c} \beta^{2}-\left(I+J^{r c}\right)^{2} \gamma^{2}>0$ typically holds, which guarantees the existence of optimal pricing for the DCR. By analysing the differentials of optimal prices $p_{o}^{r c *}$ and $p_{r}^{r c *}$ with respect to $\theta$, Lemma 3 can be obtained.

Lemma 3. Under the relaxed cross-channel return mode, the optimal channel pricing of the DCR will increase with the increase of their channel preference.

Proof. Omitted due to its similarity to the proof of Lemma 1.

As with Propositions $1-3$, it is also shown that the optimal channel prices of the DCR depend on the value of other parameters. However, unlike Propositions 1 and 2, the original channel return, the fixed cross-channel return, and the relaxed cross-channel return simultaneously coexist, and customers can choose the return channel according to convenience or other factors. Similarly, once the values of these exogenous parameters are determined, the DCR can use the pricing formulas in Proposal 3 to set the optimal channel prices under the relaxed crosschannel return mode. The conclusion of Lemma 3 is similar to that of Lemmas 1 and 2, which still shows that the DCR should set a higher retail price for the channel with high customer channel preference to obtain higher system profit.

Above, we have given the analytical solutions for the optimal channel pricing of products under different return modes; thus, we can obtain the channel profit and total system profit of the DCR. However, regardless of the optimal channel pricing, the channel profit, or the total system profit, all these analytical expressions contain exogenous parameters such as the customer channel preference coefficient $(\theta)$ and return rates of each channel $(r, w, v)$. Although the relationship between the optimal channel pricing and the customer channel preference is discussed in the lemma, we are more concerned with the influence of return rates and customer channel preferences on the optimal channel pricing, channel profit, and total system profit of the DCR under different return modes. Most of these results are 
fractional function relations of exogenous parameters such as return rates and customer channel preference, and the values of exogenous parameters are uncertain, so it is difficult to obtain valuable deterministic results by directly comparing and analysing the optimal channel pricing and related profits. Therefore, to further refine our managerial insights into the selection of a return mode for a DCR, we numerically describe the influence of the key parameters on the DCR's system profit and channel pricing in Section 7 .

\section{Numerical Examples and Sensitivity Analysis}

In Sections 4-6, we described three possible return modes of a dual-channel retailer that implements DCRS and illustrated how to determine the optimal channel pricing decisions of products under different return modes. In this section, we seek the answers to the following questions through the numerical study: what is the system performance of the DCR under different return modes? What are the effects of customer channel preferences and return rates on the system performance and optimal channel prices of the DCR? How does a DCR choose the appropriate return mode for different customer channel preferences and return rate environments? These questions are addressed to provide more detailed managerial insights.

The parameters used in this study are described in Table 2 .

\subsection{The Effect of Customer Channel Preferences and Return} Rates on Total System Profit. We first study the impact of the customer preference for offline channel $\theta$ on the DCR's system total profit. After many numerical experiments, we find that when the return rate of each channel varies within a certain range, the total system profit of the DCR is always the convex function of the customer preference for the offline channel $\theta$.

As shown in Figure 4(a) $(r=0.2, v=0.2$, and $w=0.2)$, as the customer preference for the offline channel $\theta$ increases, the total system profit of the DCR under the three return modes first decreases and then increases. This indicates that there is a significant difference in customer preferences for the two channels; that is, when the difference between $\theta$ and $1-\theta$ is large, it easier for the DCR to obtain a larger total system profit. The underlying causes of this result can be clearly observed from Figure 4(b): with an increase in customer preference for the offline channel $\theta$, the profit of the offline channel gradually increases while the profit of the online channel gradually decreases, and when $\theta$ is relatively low ( $1-\theta$ is relatively high), the range of the decrease in online channel profit is greater than the increase in offline channel profit. Thus, the total profit of the system shows a downward trend; when $\theta$ is relatively high ( $1-\theta$ is relatively low), the situation is exactly the opposite, and the total profit of the system is increasing. Furthermore, we find that for the three return modes, there is always a certain $\theta^{i *}$ that makes $\pi_{r}^{i *}=\pi_{o}^{i *}(i=o c, f c$, and $r c)$, and the total profit of the system obtained by the DCR is the smallest in this case.
TABle 2: Parameter settings.

\begin{tabular}{|c|c|}
\hline Symbol & Value and description \\
\hline$k_{r}$ & $\begin{array}{l}0.7 \text { (probability of offline original channel } \\
\text { return that is resalable) }\end{array}$ \\
\hline$k_{o}$ & $\begin{array}{c}0.6 \text { (probability of online original channel } \\
\text { return that is resalable) }\end{array}$ \\
\hline$k_{o r}$ & $\begin{array}{c}0.6 \text { (probability of online cross-return } \\
\text { offline that is resalable) }\end{array}$ \\
\hline$c$ & 20 (unit purchase cost) \\
\hline$d$ & 1 (unit collection cost of returns) \\
\hline$t$ & 2 (unit freight) \\
\hline$s$ & 5 (salvage value) \\
\hline$\alpha$ & $1000($ potential market size $)$ \\
\hline$\theta$ & $0.35,0.65$ (offline customer preference) \\
\hline$\beta$ & 8 (own-price sensitivity of a channel) \\
\hline$\gamma$ & 4 (cross-price sensitivity of a channel) \\
\hline
\end{tabular}

Although the profit relationship shown in Figures 4(a) and 4 (b) is the result of $r=0.2, v=0.2$, and $w=0.2$, the above conclusion is still valid even if the values of $r, v$, and $w$ change within a certain range (such as $(0,0.4))$. From this, we can obtain the following managerial insight:

Insight 1. After learning the return rates of different channels, the DCR should fully analyse the characteristics of its potential customer groups and use the unique advantages of the offline and online channels to attract as many customer groups as possible to a certain channel to obtain more profits; however, customers having nearly no difference in preference between the channels will deprive the DCR of the ability to obtain more profits.

In addition, while studying how the total system profit of the DCR is affected by the change in the customer preference for the offline channel $\theta$, we repeatedly adjust the value of the return rates and identify the corresponding relationship between the return rates and the return modes. First, when the online channel return rate $w$ and the cross-channel return rate $v$ are fixed, regardless of the customer preference for the offline channel $\theta$, a change in the offline channel return rate $r$ will not affect the choice of return mode. Figure 4(a) shows the total system profit at $r=0.2$, $v=0.2$, and $w=0.2$, which satisfies $\pi^{f c *}>\pi^{o c *}>\pi^{r c *}$. If we hold the values of $v$ and $w$ constant and successively set $r=0.1$ and $r=0.3$, we can obtain Figures 5(a) and 5(b). Obviously, when $r$ is small, the total profit of the system under each return mode generally increases. In contrast, when $r$ is large, the total system profit under each return mode generally decreases, but $\pi^{f c *}>\pi^{o c *}>\pi^{r c *}$ always holds. It is not difficult to explain this because the option of returning products originally purchased offline to that channel exists in all three return modes, so a change in $r$ will affect the total profit of the system under all three return modes.

Second, the values of the online channel return rate $w$ and cross-channel return rate $v$ will affect the choice of 


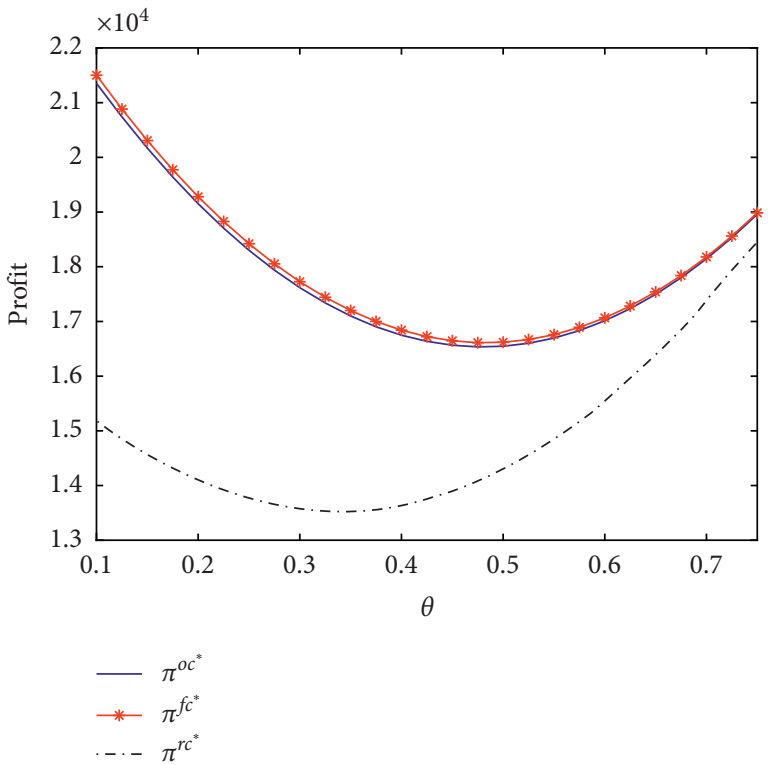

(a)

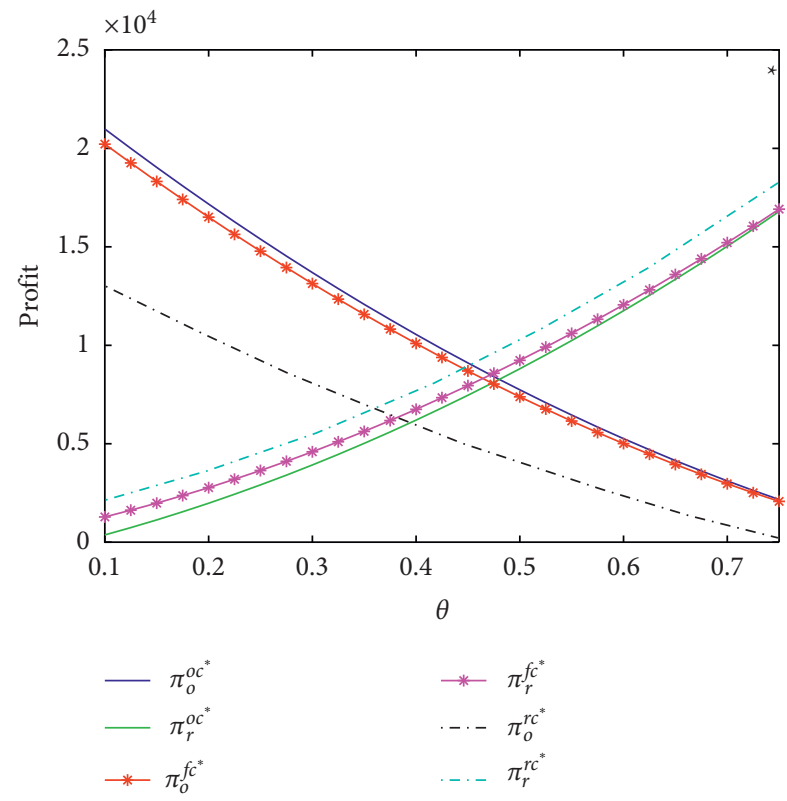

(b)

FIGURE 4: Effect of $\theta$ on the DCR's system profit: (a) the total system profit; (b) the channel profit.

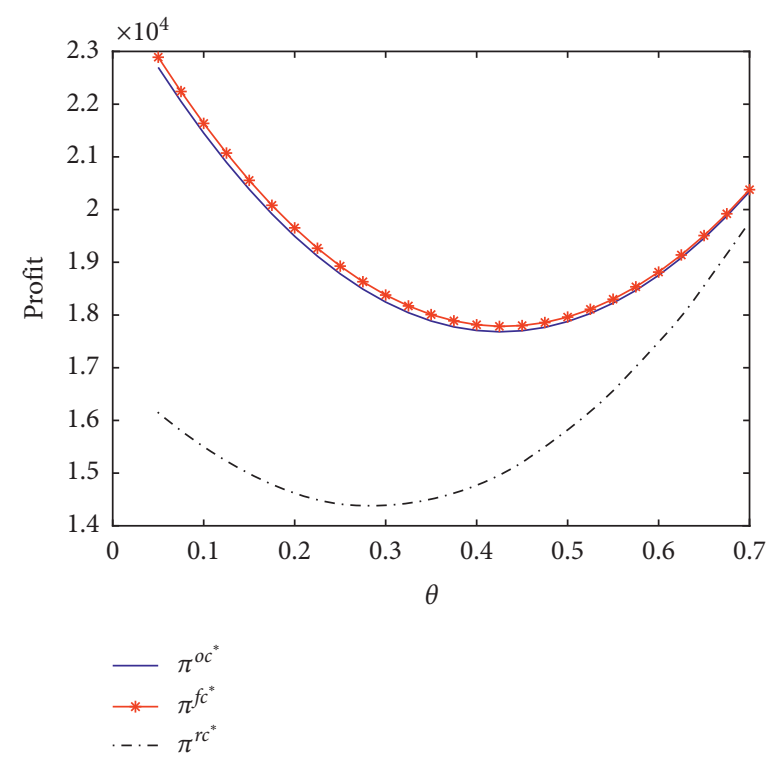

(a)

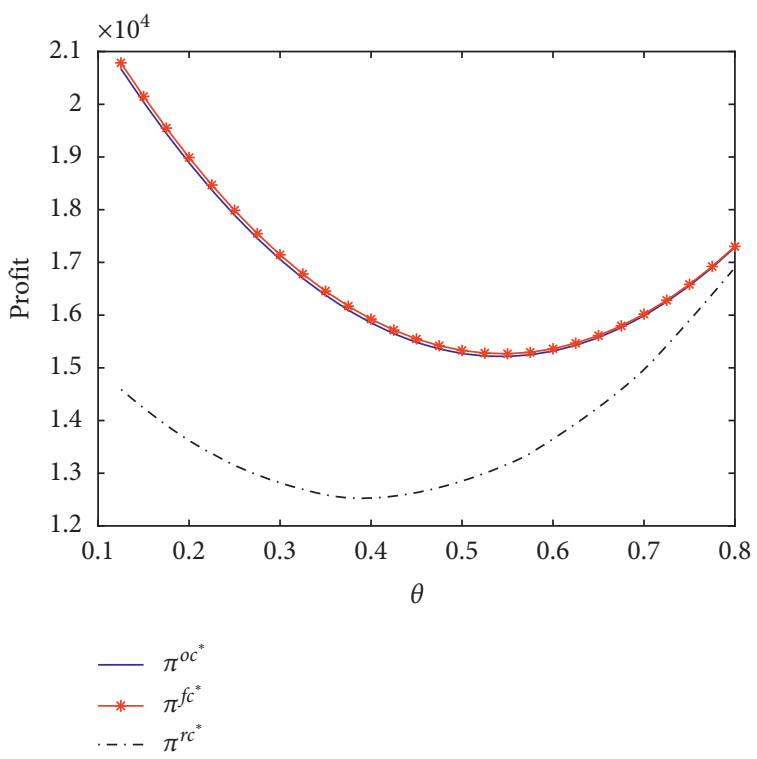

(b)

FIgURE 5: Effect of $r$ on the DCR's system profit. (a) $r=0.1(w=0.2$ and $v=0.2)$; (b) $r=0.3(w=0.2$ and $v=0.2)$.

return mode. Specifically, when the online channel return rate $w$ is larger or the cross-channel return rate $v$ is smaller, the DCR should adopt the fixed crosschannel return mode $\left(\pi^{f c *}>\pi^{o c *}>\pi^{r c *}\right)$; when the online channel return rate $w$ is smaller or the crosschannel return rate $v$ is larger, the DCR should adopt the original channel return mode $\left(\pi^{o c *}>\pi^{f c *}>\pi^{r c *}\right)$. We still use Figure 4(a) as the benchmark to obtain Figure 6 by changing the values of $w$ and $v$. Figure 6 depicts the corresponding relationship between the values of the online channel return rate $w$ and the crosschannel return rate $v$ and the choice of return mode. Finally, when changing the customer preference for the offline channel $\theta$, regardless of the values of return rates $r, v$, and $w$, the total system profit of the DCR is always the lowest under the relaxed cross-channel return mode. Regarding this, we can easily observe from the figures given above (except Figure 4(b)) why the total system profit is the smallest under the relaxed crosschannel return mode: it provides customers with more 

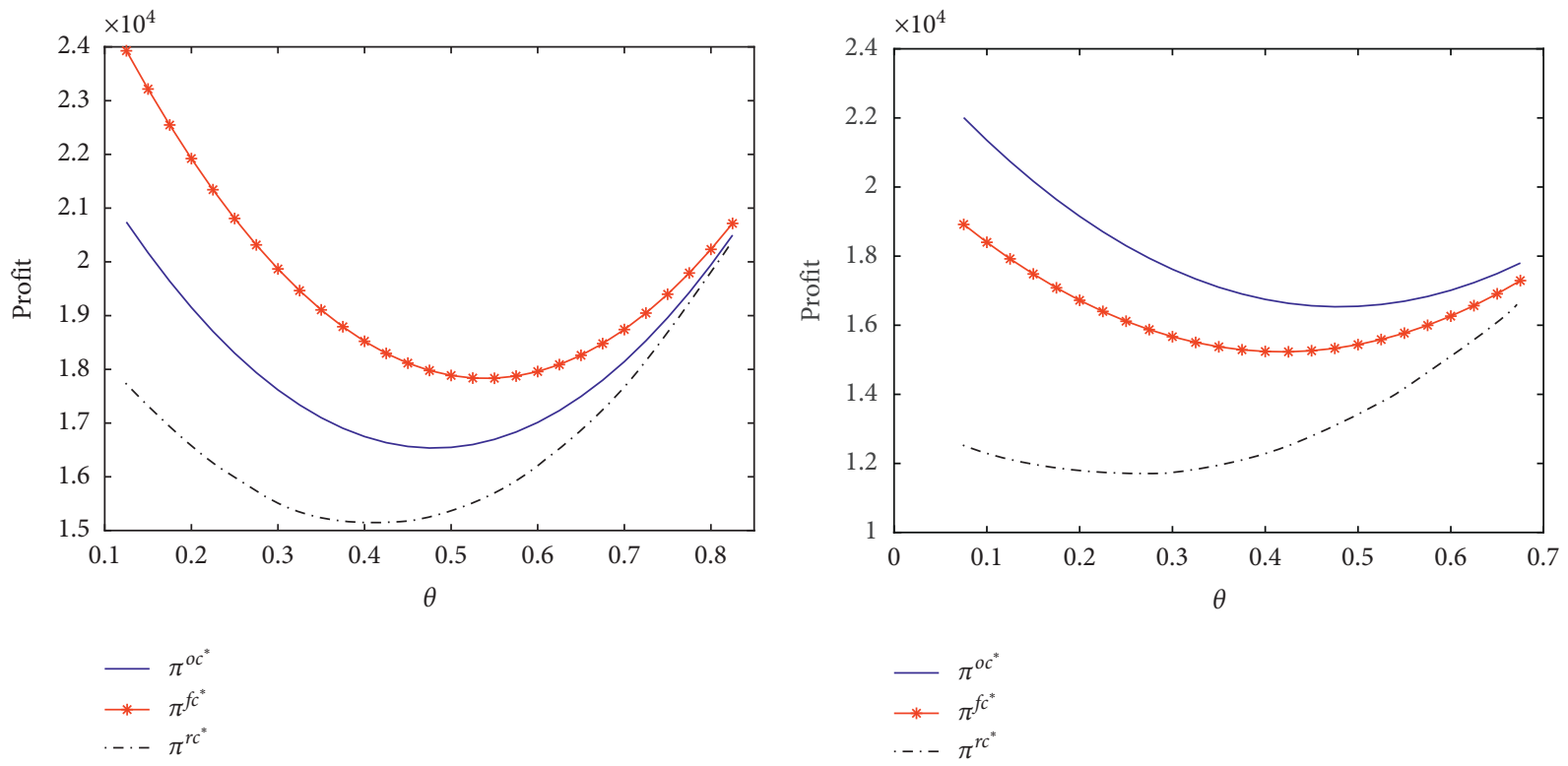

(a)
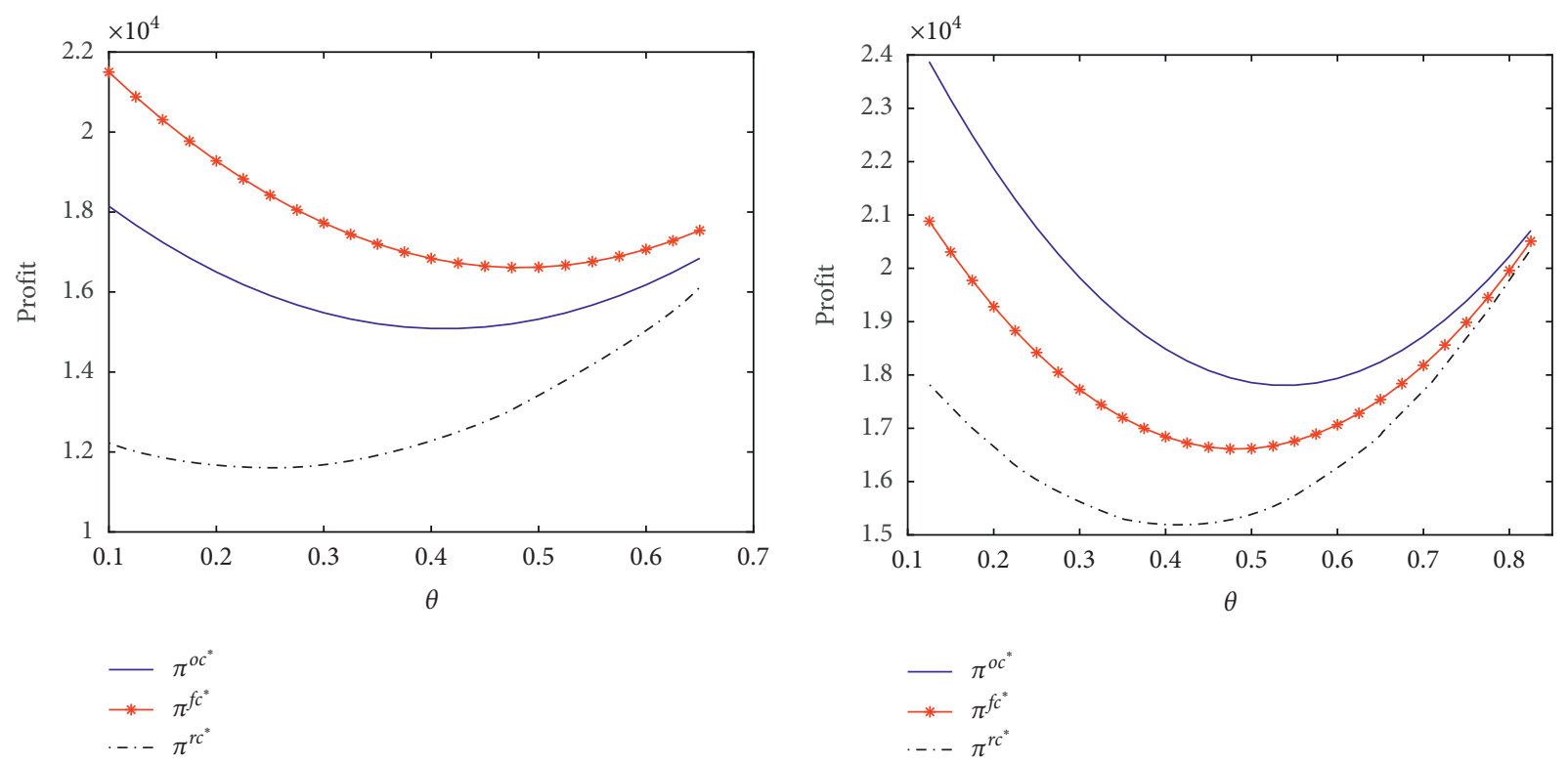

$$
\begin{aligned}
& -\pi^{o c^{*}} \\
& -\pi^{f c^{*}} \\
& . .-\pi^{r c^{*}}
\end{aligned}
$$

(c)

(d)

Figure 6: Effect of $v$ and $w$ on the DCR's system profit. (a) $r=0.2, v=0.1$, and $w=0.2$, (b) $r=0.2, v=0.3$, and $w=0.2$, (c) $r=0.2, v=0.2$, and $w=0.3$, and (d) $r=0.2, v=0.2$, and $w=0.1$.

return options, and customers who are not satisfied with their purchases can choose to return through the offline channel, the online channel, or across channels. Therefore, compared to the first two return modes, the relaxed cross-channel return mode will generate more returns and in turn decrease actual sales, which ultimately lead to lower profit for the DCR. Based on the above analysis, we obtain Insight 2 .

Insight 2. The DCR should choose the optimal return mode based on the value of the online channel return rate $w$ and the cross-channel return rate $v$ : when the online channel return rate $w$ is high or the cross-channel return rate $v$ is low, the fixed cross-channel return mode should be adopted; otherwise, the original channel return mode should be adopted. The offline channel return rate $r$ does not affect the choice of return mode.

7.2. The Effect of Customer Channel Preference and Return Rates on Pricing Strategies. In Section 7.1, we learned that the DCR can obtain a higher profit when the difference between the customer preference for the offline channel $\theta$ and the online channel $1-\theta$ is large. Therefore, in the following 
analysis, we continue to use the parameter values in Table 2, and let $\underline{\theta}=0.35$ and $\bar{\theta}=0.65$ to indicate a low customer preference for the offline channel (a high customer preference for the online channel, $1-\underline{\theta}=0.65$ ) and a high customer preference for the offline channel (a low customer preference for the online channel, $1-\bar{\theta}=0.35$ ), respectively. Our aim here is to determine how return rates impact channel pricing and refine the corresponding managerial insights.

7.2.1. Return Rate of the Offline Channel $r$. We let the return rate of the offline channel $r$ change within a certain range and consider the nonnegative limits of variables (such as price, demand, and profit) to simulate the change in channel prices with the return rate of the offline channel $r$, as shown in Figure 7. Figure 7 shows that regardless of the customer channel preference, the sales price of the offline channel increases in $r$, while the sales price of the online channel decreases in $r$. The increase in $r$ means that the return quantity of the offline channel increases and that the actual sales quantity decreases. The increase in the sales price of the offline channel, on the one hand, reduces the negative effect of returns and compensates for the loss of profits caused by the increase in the returns. On the other hand, it realizes the shift in the DCR' sales from the offline channel to online channel. Similarly, the sales price in the online channel is decreased when $r$ increases with the aim of attracting more customers at a low price, thereby transferring some of the lost sales from online to offline. Under an extremely high $r$, the DCR can use the offline physical store as a display channel and the online store as a transaction channel. Note that although Figure 7 depicts the case in which the return rate of the offline channel $r$ varies within a relatively large range, in fact, as we explained in the introduction, the value of $r$ tends to be relatively small, so we can completely ignore the variation in the range of $r>0.5$.

Moreover, by comparing Figures 7(a) and 7(b), we find that channel pricing is positively correlated with customer channel preference. That is, the optimal pricing of the offline channel of the DCR satisfies $p_{r}^{i *}(\underline{\theta})<p_{r}^{i *}(\bar{\theta})$; similarly, for the optimal pricing of the online channel, $p_{o}^{i *}(1-\underline{\theta})>p_{o}^{i *}(1-\bar{\theta})$. The approach of using high prices when the customer channel preference is high and low prices when the customer channel preference is low can to some extent eliminate the negative impact of returns and thus yield more profits from the market. From the above analysis, we can obtain the following conclusions: when the return rate of the offline channel $r$ increases, it is necessary for the DCR to increase the sales price in the offline channel and appropriately reduce the sales price in the online channel to shift sales from offline to online; moreover, for a given channel, the DCR should adopt a high price strategy when the customer channel preference is high and a low price strategy when the customer preference is low to eliminate the negative impact of returns to obtain more profits.

7.2.2. Online Channel Return Rate $w$ and Cross-Channel Return Rate $v$. Since both the online channel return rate $w$ and the cross-channel return rate $v$ reflect the return situation of the online channel, this section simultaneously analyses the impact of $w$ and $v$ on channel pricing. We also assign $\underline{\theta}=0.35$ and $\bar{\theta}=0.65$ and let $w$ and $v$ vary within a certain range.

Unlike the offline channel return rate $r$, the online channel return rate does not exist in the fixed cross-channel return mode (it can be regarded as 0 ), so the channel pricing, sales quantity, and profit in the fixed cross-channel return mode will not be affected by $w$. Similarly, the channel pricing, sales volume, and profit of the original channel return mode are also not affected by the crosschannel return rate $v$. We can clearly see in Figure 8 that when the online channel return rate $w$ varies within a certain range, the channel prices $p_{o}^{f c *}$ and $p_{r}^{f c *}$ of the fixed cross-channel return mode are constant (Figures $8(\mathrm{a})$ and $8(\mathrm{~b}))$ and that the channel prices $p_{o}^{o c *}$ and $p_{r}^{o c *}$ of the original channel return mode follow the same trend as with the change in the cross-channel return rate $v$ (Figures $8(\mathrm{c}$ ) and $8(\mathrm{~d}))$. Apart from the above two special situations, we can also observe similarities with the effect of the offline channel return rate $r$ on channel pricing in Figure 8 . Specifically, with $w$ or $v$ increasing under different customer channel preferences, on the one hand, the channel price in the online channel will increase to reduce the negative impact of returns, and the sales of the online channel will decrease simultaneously; on the other hand, the price in the offline channel is reduced to attract more customers and transfer part of the lost sales from the online channel to the offline physical store. Under an extremely high $w$ and/or $v$, the DCR should use the online store as an information channel and the offline physical store as the transaction channel.

In addition, by comparing Figures $8(a)-8(d)$, we find that channel pricing is positively related to the corresponding customer channel preference, that is, $p_{r}^{i *}(\underline{\theta})<p_{r}^{i *}(\bar{\theta})$ and $p_{o}^{i *}(1-\underline{\theta})>p_{o}^{i *}(1-\bar{\theta})$. In fact, a higher customer channel preference means a larger market share and increasing the price in the channel with the higher customer channel preference can improve the profit potential of the dual-channel system. Following the above analysis, we can also draw a similar conclusion to that drawn for the return rate of the offline channel: when the return rate of the online channel $w$ and/or the cross-channel return rate $v$ increase, it is necessary for the DCR to increase the sales price in the online channel and appropriately reduce the sales price in the offline channel to compensate for the loss of profits caused by returns and to transfer sales from online to offline. The price in a given channel with a high customer channel preference should be greater than that in one with a low customer channel preference to improve the system's profit opportunities.

Combining the full analysis and conclusions in Section 7.2, we can propose the following insight for DCRs:

Insight 3 . The DCR should consider the return rate of a channel and customer channel preferences when conducting channel pricing: when the return rate of a channel is high, the price in this channel should be 


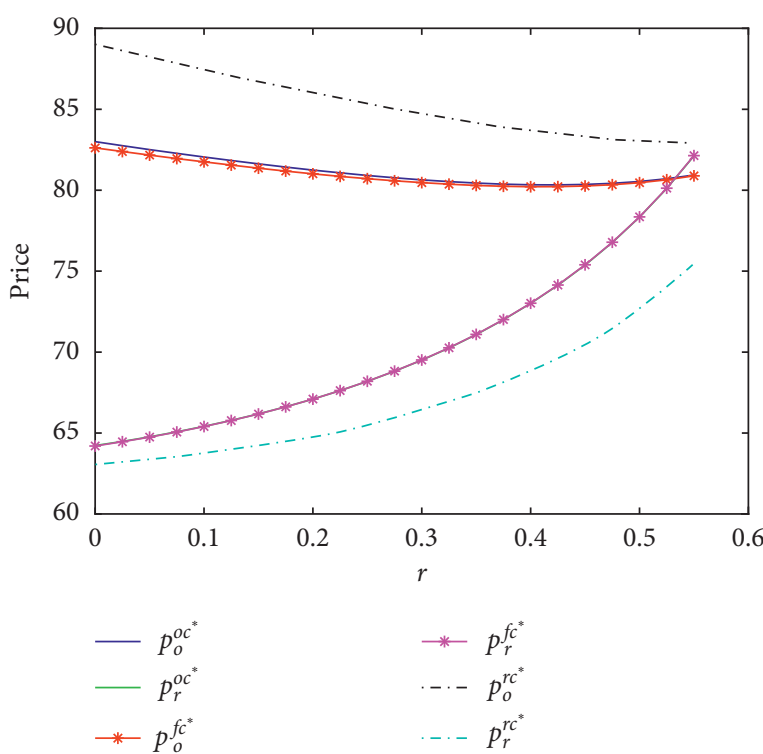

(a)
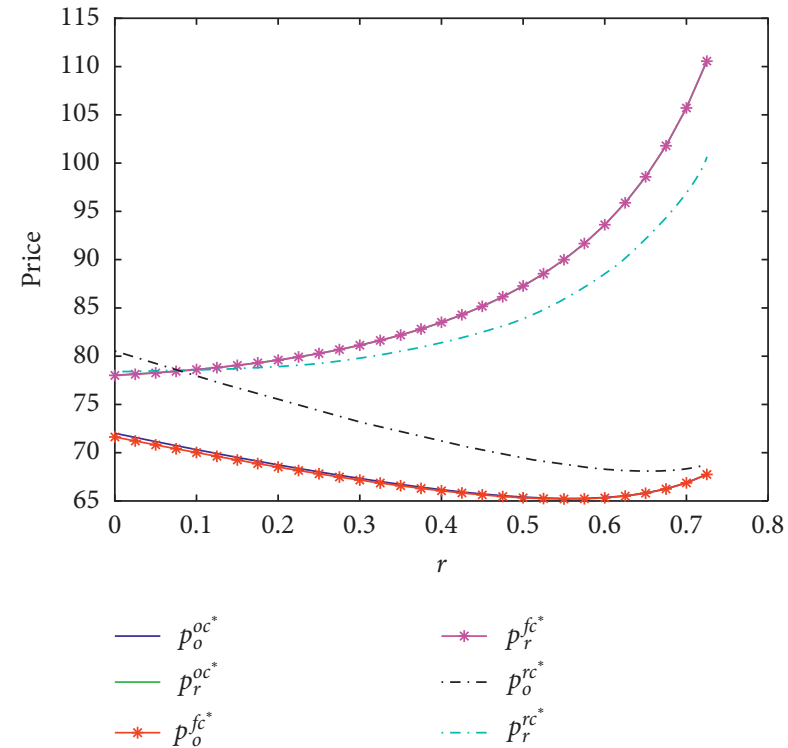

(b)

Figure 7: Effect of $r$ on channel prices under different $\theta$ : (a) low $\theta(\theta=0.35)$; (b) high $\theta(\theta=0.65)$.
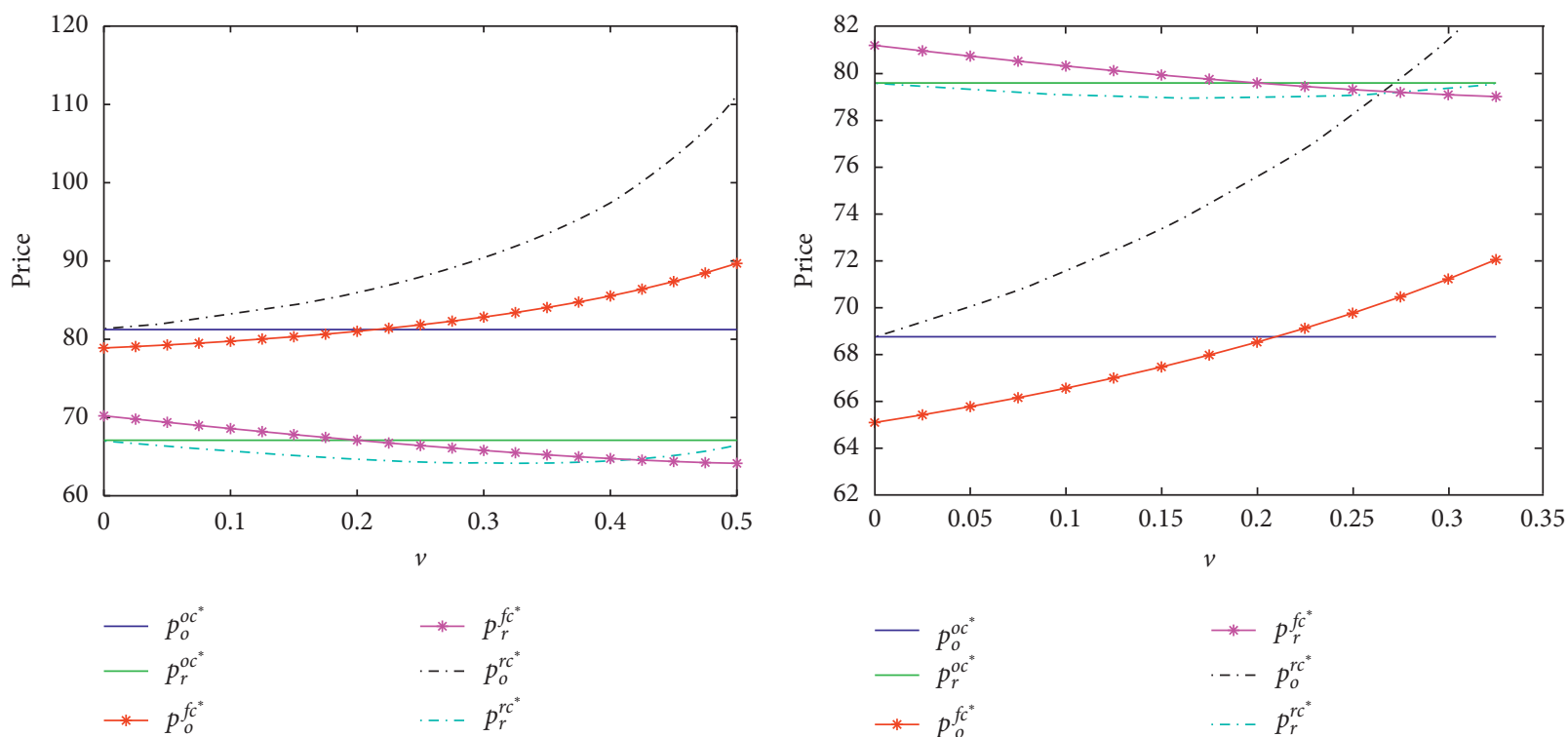

(a)
$\rightarrow p_{r}^{f c^{*}}$
$-\cdot p_{o}^{r c}$
$-\cdot p_{r}^{r c}$

(b)

Figure 8: Continued. 


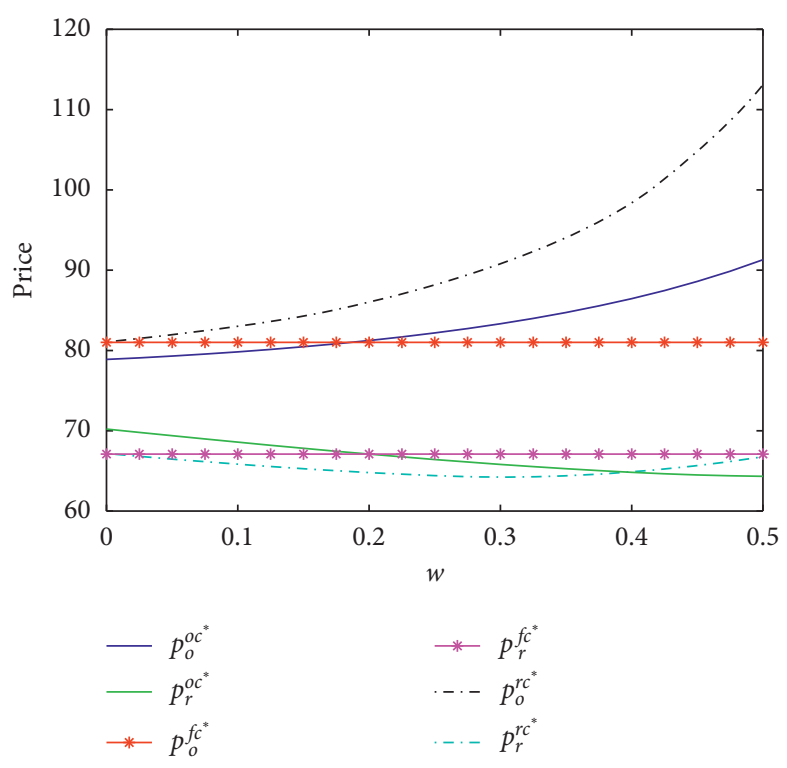

(c)

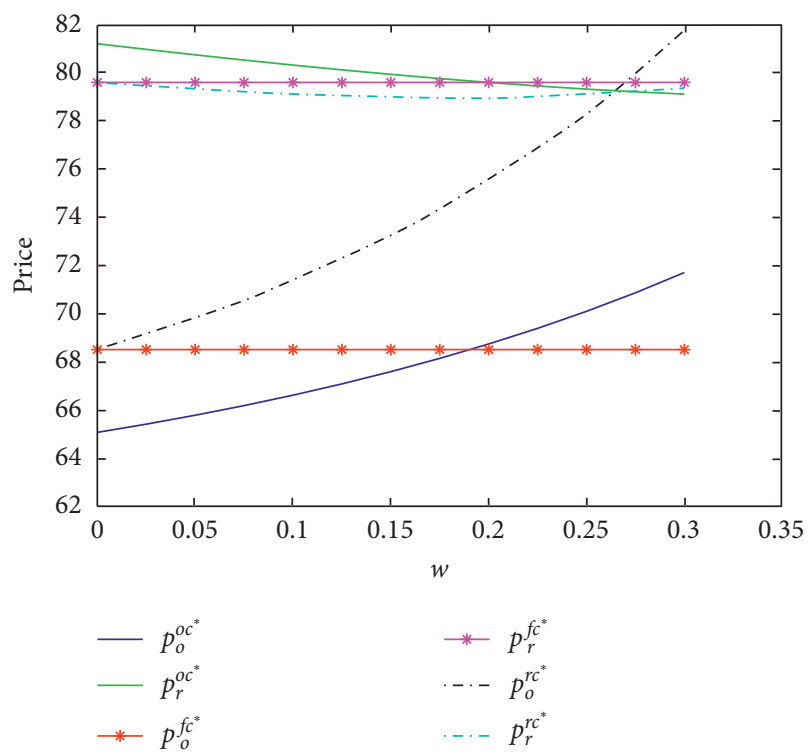

(d)

Figure 8: Effect of $v$ and $w$ on channel prices under different $\theta$ : (a) low $\theta(\theta=0.35)$, (b) high $\theta(\theta=0.65)$, (c) low $\theta(\theta=0.35)$, and (d) high $\theta$ $(\theta=0.65)$.

increased and the price in the competitive channel should be reduced, which not only compensates for the loss caused by the returns but also transfers sales between channels; under a given return rate, the price of a channel with a high customer preference should generally be greater than that of one with a low customer preference to maximize the system's profit opportunities.

Insight 4 . In the case of an extremely high return rate for a certain channel, the DCR should redefine the functions of the two channels: if the return rate of the offline channel $r$ is extremely high, then the offline physical store should be used as a display channel and the online store should be used as the transaction channel; if the return rate of the online channel $w$ and/ or the cross-channel return rate $v$ is extremely high, then the offline physical store should be used as the transaction channel while the online store should be used as an information channel.

\section{Conclusions}

This paper examines the selection of return mode and channel pricing when a DCR is considered accepting returns from customers if the retailer simultaneously operates both an offline physical store and an online store. Three return modes are compared: the original channel return mode, the fixed cross-channel return mode, and the relaxed crosschannel return mode. Similar to previous works [40, 41], we argue that when a fully coordinated or centralized monopoly system uses a single decision maker, the goal of maximizing the total profit of the system can be achieved. Therefore, the optimal pricing, correlation analysis, and conclusions in this paper are all obtained under the setting of integrated decision-making for the DCR with the goal of maximizing the total profit of the system.

This study found that the degree of customer channel preference and the return rate of each channel substantially affect the choice of return mode and channel pricing strategies of the DCR. In terms of return mode, the customer channel preference will affect the system profitability of the DCR, but the choice of return mode will not be affected, and the greater the difference in customer preference between the two channels, the greater the profitability of the system. In contrast, the channel preference of customers that are almost unbiased will deprive the DCR of the opportunity to obtain more profits. Different from the customer channel preference, the value of the return rate of each channel will simultaneously affect the system profitability and the choice of the return mode of the DCR. The choice of return mode depends on the relationship between the size of the online channel return rate $w$ and that of the cross-channel return rate $v$. When $w$ is larger or $v$ is smaller, a fixed cross-channel return mode should be adopted; otherwise, the original channel return mode should be adopted. A change in the offline channel return rate $r$ will not affect the choice of return mode, but the profitability of the system will decrease with an increase in $r$. Channel pricing should be directly proportional to the return rate and the customer preference for a given channel but inversely proportional to the return rate of its competing channel. When the return rate of a certain channel is high, a higher sales price should be set for that channel, and the sales price of the other channel should be appropriately reduced to compensate for the loss of profits caused by the high return rate and transfer sales from the high return rate channel to the low return rate channel. 
In addition, when the return rate of a certain channel is constant, its channel pricing is also directly proportional to the customer preference for that channel; that is, the price when the customer channel preference is high should be greater than when the channel preference is low, which is more likely to obtain higher system profits.

As mentioned many times above, in this work, we treat the DCR as the only decision maker in the system that makes integrated decisions with the goal of maximizing the total profit at the organizational level rather than the channel level. This view can also be verified in the analysis of the above numerical examples. For example, when the return rate of a channel is extremely high, that channel should be used as a display (physical store) or information (online store) channel, and all sales should be concentrated in the other channel, which is impossible in a decentralized decision-making system. The system profit in the case of integrated decisionmaking depends on the degree of coordination between channels and the profitability of the whole supply chain. However, this study does not involve other members of the dual-channel supply chain (such as suppliers), nor does it discuss the situation of decentralized decision-making. Although we argue that integrated decision-making by a DCR is more conducive to system profitability, the situation in which stores of different channels compete as independent departments and make separate decisions is also widespread in reality. Therefore, an extension of this study would be to consider returns in a dual-channel supply chain, for example, when the supplier accepts the return of some nonresalable products, or to discuss the situation where there is competition between the two channels in decentralized decisionmaking. Moreover, the return issue discussed in this study involves only a single product, and the channel demand for the product is a linear function of the channel price; we do not consider the simulative effect of the return policy on demand. Therefore, another extension of this study is to consider the return problem with multiple products, which can be competitive products or complementary products, or to introduce the stimulating effect of the return policy for customers into the existing demand function. Certainly, this would increase the complexity of the model, and it may even be difficult to derive analytical solutions for the model; these issues need further study.

\section{Data Availability}

The data used to support the findings of this study are included within the article.

\section{Conflicts of Interest}

The authors declare no conflicts of interest.

\section{Acknowledgments}

This project was funded by the Ministry of Education of the People's Republic of China (16YJA630017), the National Natural Science Foundation of China (NSFC) (71771055), the Natural Science Foundation of Anhui Province
(KJ2019A0520), the Horizontal Cooperation Project of Fuyang Municipal Government (XDHXPT201704), and the Key Project of Youth Talent Foundation of Fuyang Normal University (RCXM201901).

\section{References}

[1] J. Zhang, P. W. Farris, J. W. Irvin, T. Kushwaha, T. J. Steenburgh, and B. A. Weitz, "Crafting integrated multichannel retailing strategies," Journal of Interactive Marketing, vol. 24, no. 2, pp. 168-180, 2010.

[2] Y. Akçay, T. Boyacı, and D. Zhang, "Selling with money-back guarantees: the impact on prices, quantities, and retail profitability," Production and Operations Management, vol. 22, no. 4, pp. 777-791, 2013.

[3] J. Chen and P. C. Bell, "The impact of customer returns on pricing and order decisions," European Journal of Operational Research, vol. 195, no. 1, pp. 280-295, 2009.

[4] J. Mostard and R. Teunter, "The newsboy problem with resalable returns: a single period model and case study," European Journal of Operational Research, vol. 169, no. 1, pp. 81-96, 2006.

[5] A. Krishnamoorthy, D. Shajin, and B. Lakshmy, "On a queueing-inventory with reservation, cancellation, common life time and retrial," Annals of Operations Research, vol. 247, no. 1, pp. 365-389, 2016.

[6] A. Krishnamoorthy, D. Shajin, and B. Lakshmy, "GI/M/1 type queueing-inventory systems with postponed work, reservation, cancellation and common life time," Indian Journal of Pure and Applied Mathematics, vol. 47, no. 2, pp. 357-388, 2016.

[7] A. Krishnamoorthy, D. Shajin, and V. Narayanan, "Inventory with positive service time: a survey," 2019.

[8] B. McWilliams, "Money-back guarantees: helping the lowquality retailer," Management Science, vol. 58, no. 8, pp. 1521-1524, 2012.

[9] J. Heydari, T.-M. Choi, and S. Radkhah, "Pareto improving supply chain coordination under a money-back guarantee service program," Service Science, vol. 9, no. 2, pp. 91-105, 2017.

[10] T. Suwelack, J. Hogreve, and W. D. Hoyer, "Understanding money-back guarantees: cognitive, affective, and behavioral outcomes," Journal of Retailing, vol. 87, no. 4, pp. 462-478, 2011.

[11] M. A. Ülkü, L. C. Dailey, and H. M. Yayla-Küllü, "Serving fraudulent consumers? The impact of return policies on retailer's profitability," Service Science, vol. 5, no. 4, pp. 296-309, 2013.

[12] W. Li, J. Chen, G. Liang, and B. Chen, "Money-back guarantee and personalized pricing in a Stackelberg manufacturer's dual-channel supply chain," International Journal of Production Economics, vol. 197, pp. 84-98, 2018.

[13] J. Stock, T. Speh, and H. Shear, "Many happy (product) returns," in Harvard Business Review, vol. 80, p. 16, Harvard Business Publishing, Boston, MA, USA, 2002.

[14] J. A. Petersen and V. Kumar, "Perceived risk, product returns, and optimal resource allocation: evidence from a field experiment," Journal of Marketing Research, vol. 52, no. 2, pp. 268-285, 2015.

[15] X. Su, "Consumer returns policies and supply chain performance," Manufacturing \& Service Operations Management, vol. 11, no. 4, pp. 595-612, 2009.

[16] W. Chu, E. Gerstner, and J. D. Hess, "Managing dissatisfaction: how to decrease customer opportunism by partial 
refunds," Journal of Service Research, vol. 1, no. 2, pp. 140-155, 1998.

[17] Y. Li, L. Xu, and D. Li, "Examining relationships between the return policy, product quality, and pricing strategy in online direct selling," International Journal of Production Economics, vol. 144, no. 2, pp. 451-460, 2013.

[18] L. Hsiao and Y.-J. Chen, "Retailer's rationale to refuse consumer returns in supply chains," Naval Research Logistics (NRL), vol. 62, no. 8, pp. 686-701, 2015.

[19] S. Davis, E. Gerstner, and M. Hagerty, "Money back guarantees in retailing: matching products to consumer tastes," Journal of Retailing, vol. 71, no. 1, pp. 7-22, 1995.

[20] S.-Y. Chang and T.-Y. Yeh, "A two-echelon supply chain of a returnable product with fuzzy demand," Applied Mathematical Modelling, vol. 37, no. 6, pp. 4305-4315, 2013.

[21] J. Chen and P. C. Bell, "The impact of customer returns on supply chain decisions under various channel interactions," Annals of Operations Research, vol. 206, no. 1, pp. 59-74, 2013.

[22] J. Chen and H. Zhang, "The impact of customer returns on competing chains," International Journal of Management Science and Engineering Management, vol. 6, no. 1, pp. 58-70, 2011.

[23] J. Chen and P. C. Bell, "Implementing market segmentation using full-refund and no-refund customer returns policies in a dual-channel supply chain structure," International Journal of Production Economics, vol. 136, no. 1, pp. 56-66, 2012.

[24] T.-M. Choi, N. Liu, S. Ren, and P. Hui, "No refund or fullrefund: when should a fashion brand offer full refund consumerreturn service for mass customization products?," Mathematical Problems in Engineer, vol. 2013, Article ID 561846, 14 pages, 2013.

[25] H. Wang, "Do returns policies intensify retail competition?" Marketing Science, vol. 23, no. 4, pp. 611-613, 2004.

[26] V. Padmanabhan and I. P. L. Png, Reply to "do returnspolicies intensify retail competition?" Marketing Science, vol. 23, no. 4, pp. 614-618, 2004.

[27] S. Bandyopadhyay and A. A. Paul, "Equilibrium returns policies in the presence of supplier competition," Marketing Science, vol. 29, no. 5, pp. 846-857, 2010.

[28] G. P. Cachon and A. G. Kök, "Competing manufacturers in a retail supply chain: on contractual form and coordination," Management Science, vol. 56, no. 3, pp. 571-589, 2010.

[29] J. Chen and R. Grewal, "Competing in a supply chain via fullrefund and no-refund customer returns policies," International Journal of Production Economics, vol. 146, no. 1, pp. 246-258, 2013.

[30] A. Balakrishnan, S. Sundaresan, and B. Zhang, "Browse-andswitch: retail-online competition under value uncertainty," Production and Operations Management, vol. 23, no. 7, pp. 1129-1145, 2014.

[31] L. Cao and L. Li, "The impact of cross-channel integration on retailers' sales growth," Journal of Retailing, vol. 91, no. 2, pp. 198-216, 2015.

[32] G. Cai, "Channel selection and coordination in dual-channel supply chains," Journal of Retailing, vol. 86, no. 1, pp. 22-36, 2010.

[33] A. David and E. Adida, "Competition and coordination in a two-channel supply chain," Production and Operations Management, vol. 24, no. 8, pp. 1358-1370, 2014.

[34] L. Ren, Y. He, and H. Song, "Price and service competition of dual-channel supply chain with consumer returns," Discrete Dynamics in Nature and Society, vol. 2014, Article ID 565603, 10 pages, 2014.
[35] F. Zhang and C. Wang, "Dynamic pricing strategy and coordination in a dual-channel supply chain considering service value," Applied Mathematical Modelling, vol. 54, pp. 722-742, 2018.

[36] P.-S. You, S. Ikuta, and Y.-C. Hsieh, "Optimal ordering and pricing policy for an inventory system with trial periods," Applied Mathematical Modelling, vol. 34, no. 10, pp. 31793188, 2010.

[37] B. Chen and J. Chen, "When to introduce an online channel,and offer money back guarantees and personalized pricing?" European Journal of Operational Research, vol. 257, no. 2, pp. 614-624, 2017.

[38] G. Li, L. Li, S. P. Sethi, and X. Guan, "Return strategy and pricing in a dual-channel supply chain," International Journal of Production Economics, vol. 215, pp. 153-164, 2019.

[39] M. Radhi and G. Zhang, "Pricing policies for a dual-channel retailer with cross-channel returns," Computers \& Industrial Engineering, vol. 119, pp. 63-75, 2018.

[40] G. Hua, S. Wang, and T. C. E. Cheng, "Price and lead time decisions in dual-channel supply chains," European Journal of Operational Research, vol. 205, no. 1, pp. 113-126, 2010.

[41] S. Huang, C. Yang, and X. Zhang, "Pricing and production decisions in dual-channel supply chains with demand disruptions," Computers \& Industrial Engineering, vol. 62, no. 1, pp. 70-83, 2012.

[42] W.-Y. Kevin Chiang, D. Chhajed, and J. D. Hess, "Direct marketing, indirect profits: a strategic analysis of dual-channel supply-chain design," Management Science, vol. 49, no. 1, pp. 1-20, 2003.

[43] A. Arya, B. Mittendorf, and D. E. M. Sappington, "The bright side of supplier encroachment," Marketing Science, vol. 26, no. 5, pp. 651-659, 2007.

[44] X.-F. Shao, "Integrated product and channel decision in mass customization," IEEE Transactions on Engineering Management, vol. 60, no. 1, pp. 30-45, 2013.

[45] Y. Wei and F. Li, "Impact of heterogeneous consumers on pricing decisions under dual-channel competition," Mathematical Problems in Engineering, vol. 2015, Article ID 584084, 9 pages, 2015.

[46] A. Dumrongsiri, M. Fan, A. Jain, and K. Moinzadeh, "A supply chain model with direct and retail channels," European Journal of Operational Research, vol. 187, no. 3, pp. 691-718, 2008.

[47] K.-Y. Chen, M. Kaya, and Ö. Özer, "Dual sales channel management with service competition," Manufacturing \& Service Operations Management, vol. 10, no. 4, pp. 654-675, 2008.

[48] B. Dan, C. Liu, G. Y. Xu, and X. M. Zhang, "Pareto improvement strategy for service-based free-riding in a dualchannel supply chain," Asia-Pacific Journal of Operational Research, vol. 31, no. 6, 2014.

[49] W.-Y. Kevin Chiang and G. E. Monahan, "Managing inventories in a two-echelon dual-channel supply chain," European Journal of Operational Research, vol. 162, no. 2, pp. 325-341, 2005.

[50] K. Takahashi, T. Aoi, D. Hirotani, and K. Morikawa, "Inventory control in a two-echelon dual-channel supply chain with setup of production and delivery," International Journal of Production Economics, vol. 133, no. 1, pp. 403-415, 2011.

[51] M. Hoseininia, M. M. Seyyed Esfahani, F. Didehvar, and A. Haghi, "Inventory competition in a multi channel distribution system: the Nash and Stackelberg game," Scientia Iranica, vol. 20, no. 3, pp. 846-854, 2013. 
[52] S. Y. Park and H. T. Keh, "Modelling hybrid distribution channels: a game-theoretic analysis," Journal of Retailing and Consumer Services, vol. 10, no. 3, pp. 155-167, 2003.

[53] B. Dan, G. Xu, and C. Liu, "Pricing policies in a dual-channel supply chain with retail services," International Journal of Production Economics, vol. 139, no. 1, pp. 312-320, 2012.

[54] J. K. Ryan, D. Sun, and X. Zhao, "Coordinating a supply chain with a manufacturer-owned online channel: a dual channel model under price competition," IEEE Transactions on Engineering Management, vol. 60, no. 2, pp. 247-259, 2008.

[55] B. Li, P. Chen, Q. Li, and W. Wang, "Dual-channel supply chain pricing decisions with a risk-averse retailer," International Journal of Production Research, vol. 52, no. 23, pp. 7132-7147, 2014.

[56] J.-M. Chen, "Channel strategy and pricing in a dual-channel with competition," International Journal of Electronic Business Management, vol. 11, no. 4, pp. 258-267, 2013.

[57] Q. Xu, Z. Liu, and B. Shen, "The impact of price comparison service on pricing strategy in a dual-channel supply chain," Mathematical Problems in Engineering, vol. 2013, Article ID 613528, 13 pages, 2013.

[58] Y.-W. Zhou, J. Guo, and W. Zhou, "Pricing/service strategies for a dual-channel supply chain with free riding and servicecost sharing," International Journal of Production Economics, vol. 196, pp. 198-210, 2018.

[59] J. Xie, L. Liang, L. Liu, and P. Ieromonachou, "Coordination contracts of dual-channel with cooperation advertising in closed-loop supply chains," International Journal of Production Economics, vol. 183, pp. 528-538, 2017.

[60] E. Cao, C. Wan, and M. Lai, "Coordination of a supply chain with one manufacturer and multiple competing retailers under simultaneous demand and cost disruptions," International Journal of Production Economics, vol. 141, no. 1, pp. 425-433, 2013.

[61] J. Z. Zhang, O. Netzer, and A. Ansari, "Dynamic targeted pricing in B2B relationships," Marketing Science, vol. 33, no. 3, pp. 317-337, 2014.

[62] S. Panda, N. M. Modak, S. S. Sana, and M. Basu, "Pricing and replenishment policies in dual-channel supply chain under continuous unit cost decrease," Applied Mathematics and Computation, vol. 256, pp. 913-929, 2015.

[63] N. M. Modak and P. Kelle, "Managing a dual-channel supply chain under price and delivery-time dependent stochastic demand," European Journal of Operational Research, vol. 272, no. 1, pp. 147-161, 2019.

[64] X. Zhang, "Retailers' multichannel and price advertising strategies," Marketing Science, vol. 28, no. 6, pp. 1080-1094, 2009.

[65] R. Yan, "Product brand differentiation and dual-channel store performances of a multi-channel retailer," European Journal of Marketing, vol. 44, no. 5, pp. 672-692, 2010.

[66] R. Yan, "Pricing strategy for companies with mixed online and traditional retailing distribution markets," Journal of Product \& Brand Management, vol. 17, no. 1, pp. 48-56, 2008.

[67] R. Yan, J. Wang, and B. Zhou, "Channel integration and profit sharing in the dynamics of multi-channel firms," Journal of Retailing and Consumer Services, vol. 17, no. 5, pp. 430-440, 2010.

[68] H. Li, "Research on inventory sharing and pricing strategy of multi-channel retailer with channel preference in Internet environment," International Journal of Hybrid Information Technology, vol. 7, no. 6, pp. 365-374, 2014.

[69] N. M. Modak, "Exploring omni-channel supply chain under price and delivery time sensitive stochastic demand," Supply
Chain Forum: An International Journal, vol. 18, no. 4, pp. 218-230, 2017.

[70] L. Zhang and J. Wang, "Coordination of the traditional and the online channels for a short-life-cycle product," European Journal of Operational Research, vol. 258, no. 2, pp. 639-651, 2017.

[71] V. Abhishek, K. Jerath, and Z. J. Zhang, "Agency selling or reselling? Channel structures in electronic retailing," Management Science, vol. 62, no. 8, pp. 2259-2280, 2015.

[72] S. Saha, N. M. Modak, S. Panda, and S. S. Sana, "Managing a retailer's dual-channel supply chain under price- and delivery time-sensitive demand," Journal of Modelling in Management, vol. 13, no. 2, pp. 351-374, 2018.

[73] P. Zhang, Y. He, and C. Shi, "Retailer's channel structurechoice: online channel, offline channel, or dual channels?" International Journal of Production Economics, vol. 191, pp. 37-50, 2017.

[74] W. Wang, G. Li, and T. C. E. Cheng, "Channel selection in a supply chain with a multi-channel retailer: the role of channel operating costs," International Journal of Production Economics, vol. 173, pp. 54-65, 2016.

[75] S. Feng, X. Hu, A. Yang, and J. Liu, "Pricing strategy for new products with presales," Mathematical Problems in Engineering, vol. 2019, Article ID 1287968, 13 pages, 2019.

[76] P. Chatterjee, "Multiple-channel and cross-channel shopping behavior: role of consumer shopping orientations," Marketing Intelligence \& Planning, vol. 28, no. 1, pp. 9-24, 2010.

[77] S. Gallino and A. Moreno, "Integration of online and offline channels in retail: the impact of sharing reliable inventory availability information," Management Science, vol. 60, no. 6, pp. 1434-1451, 2013.

[78] B. Chen and J. Chen, "Compete in price or service?-a study of personalized pricing and money back guarantees," Journal of Retailing, vol. 93, no. 2, pp. 154-171, 2017.

[79] J. Liu, M. Ren, A. Yang, and S. Feng, "Money-back guarantee, dual money-back guarantee, and $\mathrm{O} 2 \mathrm{O}$ strategy in a manufacturer's dual-channel supply chain," Mathematical Problems in Engineering, vol. 2020, Article ID 1697082, 21 pages, 2020.

[80] J. Zhao, X. Hou, Y. Guo, and J. Wei, "Pricing policies for complementary products in a dual-channel supply chain," Applied Mathematical Modelling, vol. 49, pp. 437-451, 2017.

[81] L. Wang, H. Song, and Y. Wang, "Pricing and service decisions of complementary products in a dual-channel supply chain," Computers \& Industrial Engineering, vol. 105, pp. 223-233, 2017. 